\title{
Microwave Radiometric Remote Sensing of Volcanic Ash Clouds From Space: Model and Data Analysis
}

\author{
Mario Montopoli, Domenico Cimini, Mirko Lamantea, Michael Herzog, Hans Friedrich Graf, and \\ Frank Silvio Marzano, Senior Member, IEEE
}

\begin{abstract}
The potential of satellite passive microwave sensors to provide quantitative information about near-source volcanic ash cloud parameters is assessed. To this aim, ground-based microwave weather radar and spaceborne microwave radiometer observations are used together with forward-model simulations. The latter are based on 2-D simulations with the numerical plume model Active Tracer High-Resolution Atmospheric Model (ATHAM), in conjunction with the radiative transfer model Satellite Data Simulator Unit (SDSU) that is based on the deltaEddington approximation and includes Mie scattering. The study area is the Icelandic subglacial volcanic region. The analyzed case study is that of the Grímsvötn eruption in May 2011. ATHAM input parameters are adjusted using available ground data, and sensitivity tests are conducted to investigate the observed brightness temperatures and their variance. The tests are based on the variation of environmental conditions like the terrain emissivity, water vapor, and ice in the volcanic plume. Quantitative correlation analysis between ATHAM/SDSU forward-model columnar content simulations and available microwave radiometric brightness temperature measurements, derived from the Special Sensor Microwave Imager/Sounder (SSMIS), are encouraging in terms of both dynamic range and correlation coefficient. The correlation coefficients are found to vary from -0.37 to -0.63 for SSMIS channels from 91 to $183 \pm 1 \mathrm{GHz}$, respectively. The larger sensitivity of the brightness temperature at $183 \pm 1 \mathrm{GHz}$ to the columnar content, with respect to other channels, allowed us to consider this channel as the basis for a model-based polynomial relationship of volcanic plume height as a function of the measured SSMIS brightness temperature.
\end{abstract}

Manuscript received July 10, 2012; revised November 17, 2012, January 25, 2013, and March 10, 2013; accepted April 3, 2013. Date of publication June 5, 2013; date of current version August 30, 2013. This work was supported in part by the European Commission under the Marie Curie Fellowship within the call FP7-PEOPLE-2010-IEF, Grant 273666, and under the FP7 FUTURVOLC Project Grant 308377 within the call FP7-ENV-2012 and in part by the Department of National Civil Protection (DPC), Rome, Italy, under the IDRA Project.

M. Montopoli, M. Herzog, and H. F. Graf are with the Department of Geography, University of Cambridge, Cambridge CB2 3EN, U.K. (e-mail: mm911@cam.ac.uk; mh526@cam.ac.uk; hfg21@cam.ac.uk).

D. Cimini is with the Istituto di Metodologie per l'Analisi Ambientale, Consiglio Nazionale delle Ricerche, C.da S. Loja-Zona Industriale, 85050 Tito Scalo, Italy, and also with the Centro di Eccellenza per l'integrazione di Tecniche di Telerilevamento e Modellistica Numerica per la Previsione di Eventi Meteorologici Severi, University of L'Aquila, 67100 L'Aquila, Italy (e-mail: domenico.cimini@imaa.cnr.it).

M. Lamantea is with the Department of Information Engineering, Electronics and Telecommunications, Sapienza University of Rome, 00184 Rome, Italy (e-mail: mirkolamantea@gmail.com).

F. S. Marzano is with the Department of Information Engineering, Electronics and Telecommunications, Sapienza University of Rome, 00184 Rome, Italy, and also with the Centro di Eccellenza per l'integrazione di Tecniche di Telerilevamento e Modellistica Numerica per la Previsione di Eventi Meteorologici Severi, University of L'Aquila, 67100 L'Aquila, Italy (e-mail: marzano@die.uniroma1.it).

Color versions of one or more of the figures in this paper are available online at http://ieeexplore.iee.org.

Digital Object Identifier 10.1109/TGRS.2013.2260343
Index Terms-Ash clouds, ash microphysical model, microwave passive and active sensors, radiative transfer model.

\section{INTRODUCTION}

$\mathbf{V}$ OLCANIC eruptions can cause serious threats to human life on local to regional and even global scales [1]. Threats include health issues due to ash aspiration, the interruption of the air traffic due to the potential airplane engine failure, and climate changes induced by ash and sulfate aerosols dispersed in the stratosphere [2]. State-of-the-art countermeasures to mitigate the consequence of a volcanic eruption include direct inspection, remote sensing observations, and numerical dispersion models [3]-[5]. Tracking and quantifying ash in the atmosphere allow for the redirection of air traffic, governments to issues warnings for citizens affected by ash fallout, and the correct calculation of the Earth's energy balance due to the shielding effects of fine ash (FA) particles and aerosols. The synergy of models and remote sensing tools is probably the best way to fulfill the main requirements suggested by the civil authorities and scientific communities. Requirements can be divided into the following: 1) issuing timely warnings; 2 ) monitoring the ash plume during its evolution; and 3) quantitatively estimating the tephra, i.e., the fragmented material produced by a volcanic eruption. Due to the inherent limitations of individual measurements and methods, the characterization of the spatial and temporal scale dynamics of volcanic eruptions requires the combination of different types of observations.

There is a distinction between techniques that provide timely data during the volcanic activity and those that provide information before and after an eruptive event [6]. The monitoring of geochemical and geodetic precursor signatures has to be distinguished from near real-time observations like those from infrared or microwave remote sensors either from ground or satellite platforms. When the observation is close to the volcano vent, remote sensing instruments can be used to estimate the so-called near-source eruption parameters. The most common near-source parameters are the plume height, the tephra eruption rate, and mass [7]. The retrieval of these parameters is crucial as an input for dispersion models that are designed to quantitatively predict geographical areas likely to be affected by specific levels of ash concentrations. Remote sensing measurements of tephra can also be used for model validation purposes. On the other hand, similarly to what is often done for water clouds [9], volcanic plume models can provide the physical basis to build model-based estimators of ash cloud parameters from remote sensors. 
Traditionally, the monitoring of ash plumes is performed exploiting thermal infrared and optical channels of spaceborne radiometers [4], [5]. These measurements can be obtained from geosynchronous-Earth-orbit (GEO) and low-Earth-orbit (LEO) satellites, thus offering different spatial and temporal resolutions for ash cloud remote sensing. For GEO platforms, the advantage of a rapid sampling rate of the Earth scene has the disadvantage of a lower spatial resolution (typically larger than a few kilometers). For LEO, the revisit time may be even longer than $12 \mathrm{~h}$ but with spatial resolutions that vary from several kilometers down to meters, depending on the wavelength used by the sensor aboard LEO platforms. Moreover, thermal infrared and optical channels may suffer from strong ash cloud opacity (very often mixed with water cloud) due to the significant radiation extinction, particularly in the proximity of the volcanic source. In this respect, the exploitation of the microwave passive sensors, depending on the sensor's wavelength, may represent a good opportunity to observe the ash cloud, despite some inherent limitations [10], [11].

This work investigates the potential use of spaceborne microwave passive sensors for estimating volcanic plume parameters by comparing them to and combining them with results from a numerical model and estimates from microwave ground weather radar.

Numerical simulations of volcanic eruption plumes are generated using the Active Tracer High-Resolution Atmospheric Model (ATHAM) [15]-[18]. ATHAM outputs, together with the Satellite Data Simulator Unit (SDSU) [20], are used to generate synthetic observations of satellite-based microwave brightness temperature. SDSU is a radiative transfer model, which includes both multiple scattering and Mie extinction modules for ensembles of spherical particles. SDSU is able to simulate the response of active and passive remote sensors from microwaves to visible wavelengths. While ATHAM is a plume model specifically designed for volcanic studies, SDSU has been modified (as described in this study) to accurately describe the ash cloud electromagnetic and microphysical features as well as to ingest the outputs of ATHAM. Both ATHAM and SDSU simulations are performed in a 2-D framework, and their role in this study is to provide a likely realization of a volcanic eruption plume without claiming to exactly reproduce the case study of the Grímsvötn eruption that we analyze in this work.

The actual observations considered in this paper refer to the case study of the Grímsvötn volcanic eruption, which occurred in May 2011 in Iceland. Measurements include data from the Special Sensor Microwave Imager/Sounder (SSMIS) on a LEO platform during the Grímsvötn eruption on May 22 and a C-band ground-based weather radar, which observed the same event from a distance of approximately $260 \mathrm{~km}$.

Through the use of models and measurements, this work shall investigate the potential features of microwaves for estimating near-source ash plume parameters. Microwaves can offer useful complementary information to thermal infrared observations due to the relatively low microwave extinction and high thermal emissivity of ash clouds [10] and because they are sensitive to the whole ash column and not only to the upper part, as is typical for visible-infrared radiometers [4], [5].
The major disadvantages of detecting volcanic plumes from LEO passive microwave radiometers, compared to detection from GEO visible-infrared instruments, are the relatively poor spatial resolution and overpass repetition. They are on the order of a few kilometers around $180 \mathrm{GHz}$ up to tens of kilometers around $30 \mathrm{GHz}$ [12] and $6 \mathrm{~h}$ [9], respectively.

Section II of this paper describes the Grímsvötn case study through the available measurements. Section III introduces the ATHAM model, showing simulation results referring to the 2011 Grímsvötn eruption and providing details about the radiative transfer setup. Section IV shows the results of the forward-model simulations and the comparison with actual measurements. Conclusions are discussed in Section V.

\section{2011 GRÍMSVÖTN ERUPTION CASE STUdY}

The Grímsvötn volcano, located in the northwest of the Vatnajökull glacier in southeast Iceland is one of Iceland's most active volcanoes (e.g., [7]). The eruption in 2011 started on the late afternoon of May 21. The Grímsvötn area consists of a series of subglacial lakes that are never completely frozen due to the volcanic activity below them. Because most of Grímsvötn volcano lies underneath the Vatnajökull glacier, most of its eruptions have been subglacial with the interaction of magma and melt water from the ice, causing phreatomagmatic explosions.

\section{A. General Description of the 2011 Grímsvötn Eruption}

The Grímsvötn eruption in May 2011 was the largest eruption on Iceland within the last hundred years [21], [22]. Following the Iceland Meteorological Office (IMO) status reports, the 2011 Grímsvötn eruption is estimated to have started under the glacier at around 17:30 Universal Time Coordinate (UTC) on May 21, 2011, when an intense spike in tremor activity was detected. At around 19:00 UTC, the eruption broke the ice cover of the glacier and started spewing volcanic ash into the air. The eruption plume quickly rose to approximately $20 \mathrm{~km}$, accompanied by a series of small earthquakes. During May 22, the ash plume reached around $10 \mathrm{~km}$ in altitude, rising occasionally to $15 \mathrm{~km}$ [27].

Initially, the plume drifted to the southeast and subsequently to the north. An example of the ash plume transport is given by the MODerate-resolution Imaging Spectroradiometer (MODIS) image in Fig. 1(a). From this figure, the ash cloud is clearly visible in brown, and the spiral around the volcano vent suggests a counterclockwise rotation of the cloud system. The eruption caused disruptions to air travel in Iceland and northwestern Europe from May 22 to 25, 2011. On May 23, the eruption released more than 2000 tons of ash per second, totaling 120 million tons within the first $48 \mathrm{~h}$ [27], [28]. On May 25, the IMO confirmed that the eruption had paused at 02:40 UTC and that the volcanic activity appeared to have stopped. At 15:00 UTC, the IMO issued an update stating that no further ash plume was expected. However, there were still frequent explosions producing ash and steam clouds, some reaching a few kilometers in height. On May 26, IMO and the University of Iceland reported that ashfall was only occurring 

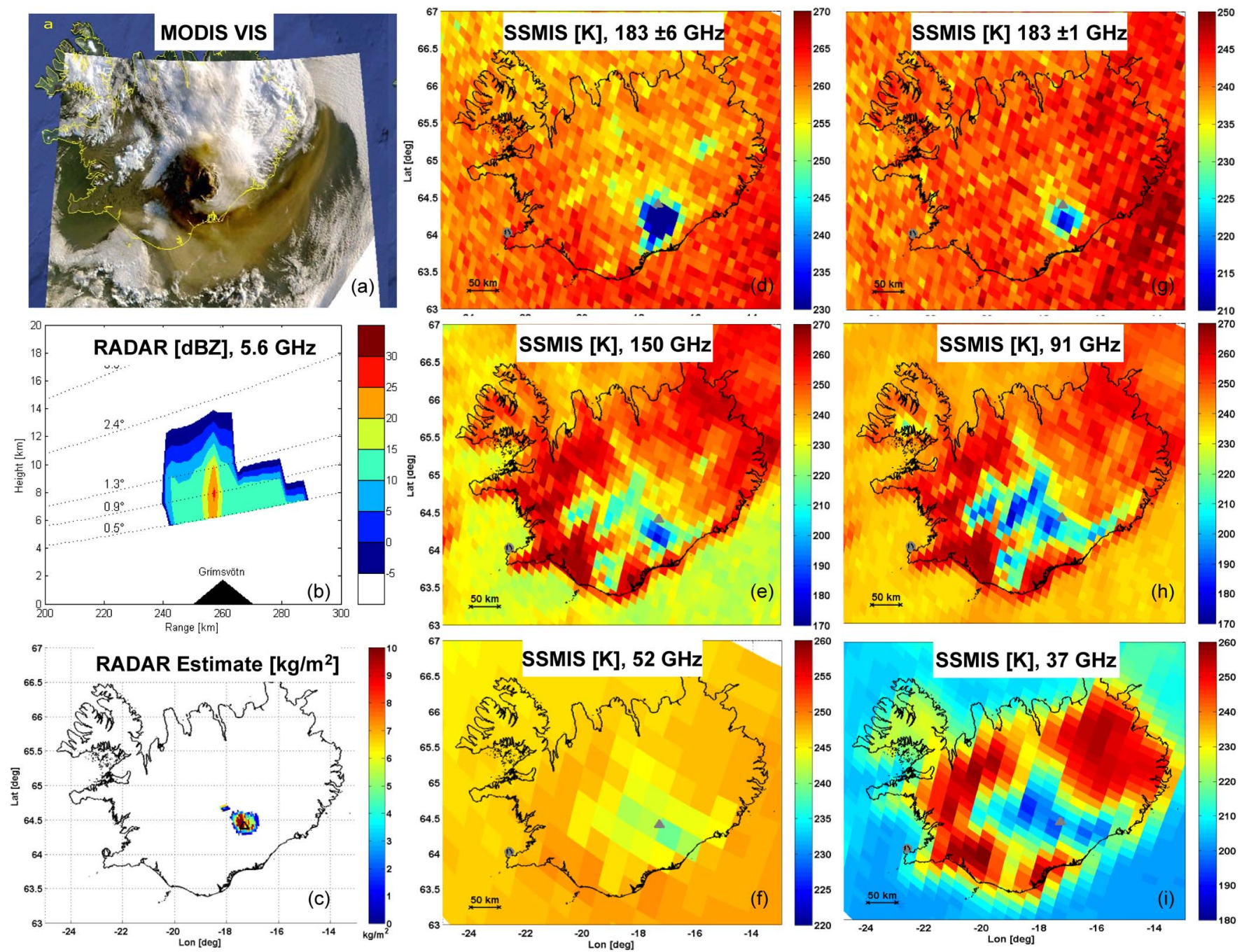

Fig. 1. Observations of the Grímsvötn eruption on May 22, 2011. (a) Geolocated natural-color image taken over Iceland, acquired from the MODIS aboard the Aqua satellite, at 1-km resolution on 05:15 UTC (courtesy of Jeff Schmaltz of MODIS Rapid Response Team at the National Aeronautics and Space Administration Goddard Space Flight Center and Google Earth-Europa Technologies, Data Scripps Institution of Oceanography, National Oceanic and Atmospheric Administration, U.S. Navy, National Geospatial-Intelligence Agency, and General Bathymetric Chart of the Oceans). (b) Vertical cross section showing the Keflavík C-band radar reflectivity (in decibels of Z) at 08:35 UTC, which is the interpolation result of the Matlab "pseudocolor" tool. (c) Ash columnar content (in kilogram square meters) derived from Keflavík C-band radar reflectivity applying the VARR technique. (d)-(i) Brightness temperature (BTs, in Kelvin) images at 08:34 UTC and frequency (in gigahertz)-per-polarization-state values of $(183 \pm 6) / \mathrm{H}, 150 / \mathrm{H}, 53 / \mathrm{V},(183 \pm 1) / \mathrm{H}, 91 / \mathrm{V}$, and 37/V GHz, respectively, acquired by SSMIS aboard the F-16 DMSP satellite. (c)-(i) Position of the Grímsvötn volcano and the Keflavík C-band radar are indicated with the gray symbols " $\triangle$ " and " $\circ$, , respectively.

close to the eruption vent. The 2011 Grímsvötn eruption officially ceased at 07:00 UTC on May 28, 2011. In terms of the Volcanic Explosivity Index (VEI) [39], it qualified as an at least of class 4 (VEI-4) eruption within a range from zero to seven, releasing more ash within the first 24 hours than Eyjafjallajökull released during its entire 2010 episode, which lasted six days.

\section{B. Remote Sensing Observations}

The Grímsvötn eruption was observed by the Keflavík ground-based C-band weather radar (5.6-GHz frequency), which is $260 \mathrm{~km}$ from the volcano vent. The eruption was also observed by the SSMIS aboard the LEO Defense Meteorological Satellite Program (DMSP) of U.S. Air Force platform orbiting at $833-\mathrm{km}$ height above ground [12], [13]. SSMIS is a conically scanning passive microwave radiometer with several channels (from about 19 to $189 \mathrm{GHz}$ ) and a swath of approximately $1700 \mathrm{~km}$. For the study of ash, the SSMIS channels shown in Fig. 1 are of particular interest. Their central frequencies and spatial samplings are as follows (in gigahertz per kilometer): $(183 \pm 6) / 12.5,150.0 / 12.5,52.0 / 37.5,(183 \pm 1) / 12.5$, $91.6 / 12.5$, and $37.0 / 25$. The angle of observation between the nadir direction and the antenna pointing direction is $45^{\circ}$.

Fig. 1 shows an example of temporally collocated SSMIS brightness temperatures at horizontal polarization, $\left(\mathrm{BT}_{H}\right)$ in Kelvin [Fig. 1(d)-(i)], radar reflectivity factor at horizontal polarization, $\left(Z_{H m}\right)$ in decibels of $Z$ as a vertical cut [Fig. 1(b)], and the volcanic ash radar retrieval (VARR) estimate of the ash content in kilogram square meters [26], [35] [Fig. 1(c)]. Available radar data cover most of the active eruption phase with nominal temporal, range, and azimuth resolutions of $5 \mathrm{~min}, 2 \mathrm{~km}$, and $0.86^{\circ}$, respectively. Due to the LEO of DMSP satellite, the temporal sampling capability of SSMIS is limited. 
Currently, three satellites of the DMSP series ensure a repeat frequency over any given area of about three overpasses per day. In Fig. 1, the depression of $\mathrm{BT}_{H}$ corresponding to cold temperatures is evident in all SSMIS channels with different intensities. This is most likely a signature of the volcanic plume produced by upwelling microwave radiation that has been emitted from the surface and scattered by ash and ice particles. A plume height of $14 \mathrm{~km}$ and a cloud horizontal spread of approximately $50 \mathrm{~km}$ from the Grímsvötn volcano vent can be seen from the radar vertical cut in Fig. 1(b). This is in qualitative agreement with the satellite $\mathrm{BT}_{H}$ depression [Fig. 1(d)-(i)]. A good qualitative correlation between $\mathrm{BT}_{H}$ depression and VARR ash columnar content is evident in Fig. 1(c). The microwave $\mathrm{BT}_{H}$ of this scene is clearly frequency and surface dependent. For example, the sea provides a relatively "cold" background at $37 \mathrm{GHz}$. Above $100 \mathrm{GHz}$, background brightness temperatures increase due to atmospheric water vapor [14]. Below $100 \mathrm{GHz}$, glaciers can provide an ambiguous signature with respect to ash clouds due to the fact that both are relatively efficient scatterers [11]. This spurious radiometric signature of the cloud-free ice cap is detected particularly to the northwest of the vent, where no ash plume is present in the visible MODIS image [Fig. 1(a)]. At around $183 \mathrm{GHz}$, the strong emission of water vapor tends to mask the surface itself, as is evident in Fig. 1(d) and (g). With increased distance from the water vapor line central frequency at $183 \mathrm{GHz}$, the contrast between background $\mathrm{BT}_{H}$ and those affected by the scattering induced by the volcanic cloud is increased. This is particularly evident comparing $183 \pm 1 \mathrm{GHz}$ with $183 \pm$ $6 \mathrm{GHz}$ (Fig. 1(g) and (d), respectively), where the latter allows for an easier identification of the volcanic cloud. The lower atmosphere channels of SSMI from 22 to $60 \mathrm{GHz}$ were not used here because of their coarse spatial resolution. Due to similar weighting functions for the two nearly transparent channels at 37 and $50 \mathrm{GHz}$, features are similar, although with the different spatial sampling characteristics listed earlier (i.e., 25 and $37.5 \mathrm{~km}$ at 37 and $50 \mathrm{GHz}$, respectively). For the channels from 22 to $60 \mathrm{GHz}$, the absorption of oxygen strongly masks the observed scene, as is already evident at $52 \mathrm{GHz}$ [Fig. 1(f)]. In this channel, the contribution from the surface is higher than that at $53 \mathrm{GHz}$ (not shown).

\section{Microwave AND NumericAL VolCANiC Plume Model}

In order to analyze and interpret the microwave radiometric signatures from space, a coupled microwave and volcanic plume model is set up. The adjustment of model parameters exploits information (i.e., particle sizes and radar observations) that we collected from the current and past subglacial Icelandic eruptions. The next two sections describe the physical and electromagnetic model components.

\section{A. Volcanic Plume Model}

ATHAM is a nonhydrostatic numerical model with applications across a broad range of atmospheric problems. In the volcanic configuration, it has been used to study the effect of large volcanic eruptions on stratospheric chemistry and the influence of physical processes on plume development [15]-[18]. For a given volcanic forcing at the lower boundary, ATHAM predicts the evolution of the gas particle mixture within the atmosphere. The concept of active tracers means that particles such as ash and hydrometeors can occur in any concentration and directly influence the dynamics and thermodynamics of the system through the equation of state. By assuming an instantaneous exchange of momentum and heat, the evolution of individual active tracers is coupled to the evolution of the momentum and temperature of the gas particle mixture, strongly reducing the number of independent prognostic variables in the model. In this paper, 2-D simulations of volcanic plumes are performed using eight incompressible tracers. Hydrometeors are split into small cloud and larger precipitation particles, including both liquid and solid phases representing cloud water, cloud ice, rain, and graupel. Two classes of gases, i.e., water vapor and sulfur dioxide, are simulated. Two tracers represent the size spectrum of tephra particles, ash particles and lapilli with volume mean diameters of 1.5 and $5 \mathrm{~mm}$, respectively.

The description of cloud microphysical processes within ATHAM is based on a bulk concept so that the hydrometeor mass is predicted, whereas number concentrations are determined from prescribed (cloud water and cloud ice) or diagnosed (rain and graupel) particle sizes [19]. In the present simulation, the formation of aggregates through ash hydrometeor interaction is ignored. Instead, ash particles and hydrometeors are assumed to coexist within the same volume as independent particles. Terminal fall velocities of particles are calculated from prescribed or diagnosed effective radii representative for the volume mean radius of the assumed Gamma particle size distribution (PSD) [15]. Nonsphericity effects are considered by modifications of the drag coefficient.

It is worth pointing out that ATHAM is not a dispersal model. Dispersal models, such as PUFF [23], REMOTE [24], FLEXPART [25], and FALL3D [3], are widely used to forecast the dispersion of ash particles and gases based on prescribed meteorological conditions. Their use helps to track regions that are likely to be subjected to ash cloud. Dispersal models provide outputs on a large spatial scale (thousands of kilometers), typically every three or six hours. They are operatively used. ATHAM, in contrast, simulates the plume dynamics in the proximity of the vent (up to approximately $100 \mathrm{~km}$ away from the vent) with temporal and spatial resolutions on the order of seconds to minutes and several tens to hundred meters, respectively. These characteristics are particularly useful when an accurate description of the plume dynamics and microphysics is needed. Here, ATHAM is utilized to provide a synthetic plume used to study the response of a microwave passive sensor.

Fig. 2 shows the output from the 2-D (altitude-distance) ATHAM simulation of the Grímsvötn eruption taken as reference scenario. ATHAM input parameters for this simulation are listed in Table I. The parameter selection has been done by comparing the ATHAM volcanic plumes with temporal sequences of radar vertical cross sections from the 2011 Grímsvötn event. For this comparison, the ATHAM output has been first converted to radar reflectivity in the geometry of the actual radar measurements (i.e., in the polar coordinates). Thus, 


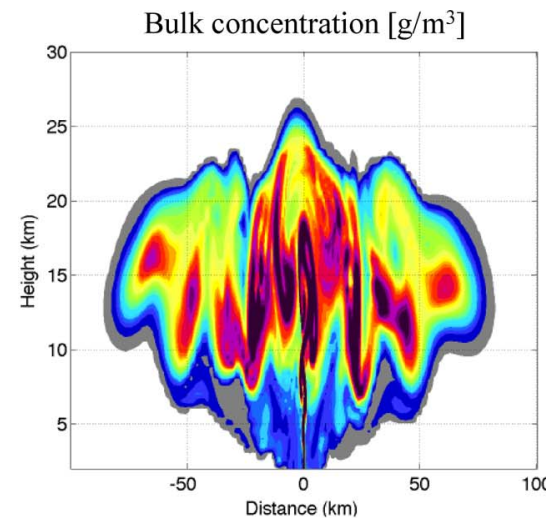

Water concentration $\left[\mathrm{g} / \mathrm{m}^{3}\right]$

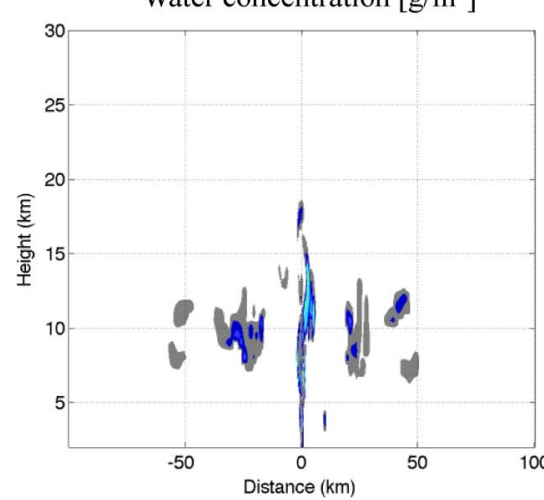

Ash concentration $\left[\mathrm{g} / \mathrm{m}^{3}\right]$

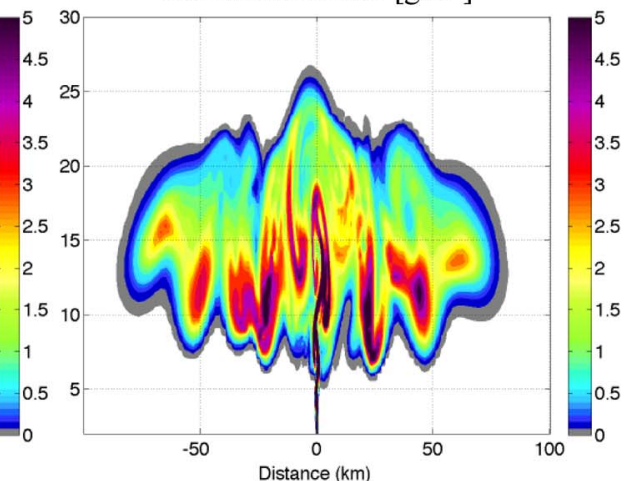

Ice concentration $\left[\mathrm{g} / \mathrm{m}^{3}\right]$

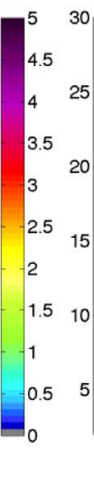

\section{ice concentration $\left[\mathrm{g} / \mathrm{m}^{3}\right]$}

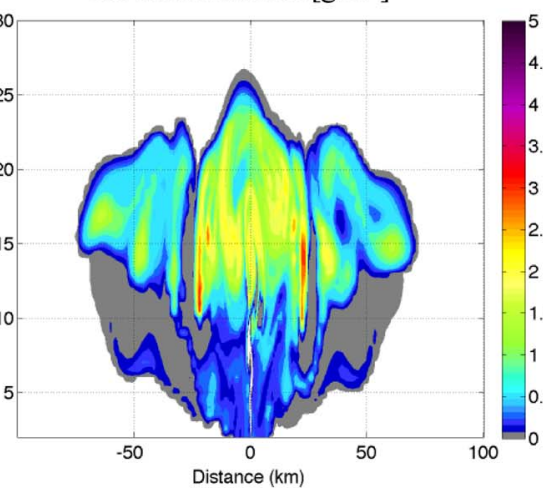

Vertical velocity $[\mathrm{m} / \mathrm{s}]$

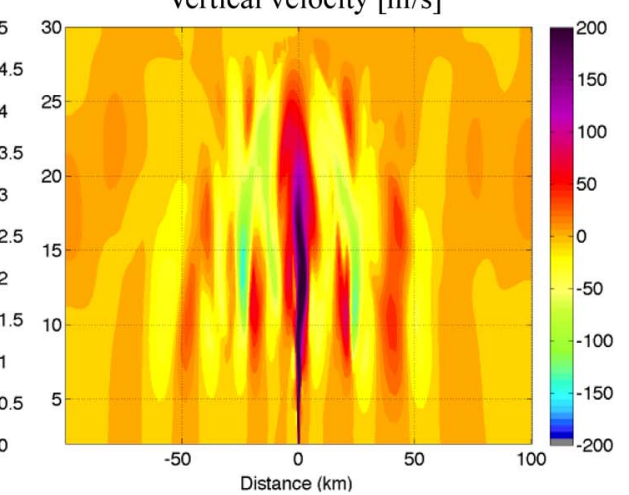

Temperature $[\mathrm{K}]$

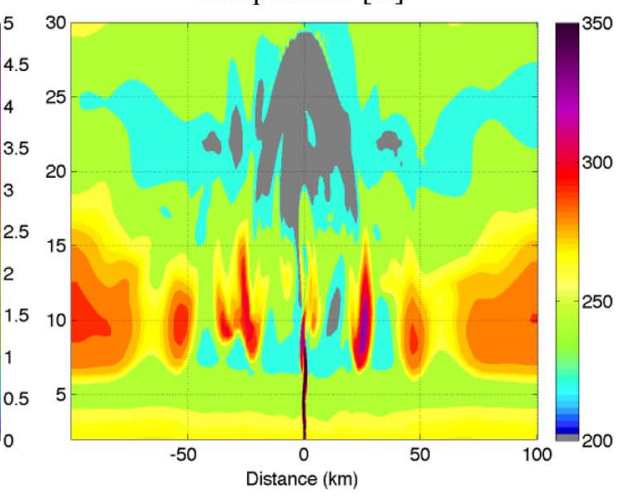

Fig. 2. Example of a volcanic plume simulation, in terms of mass concentrations $\left(C_{p}\right)$, temperature, and vertical wind, tuned for the 2011 Grímsvötn eruption event and obtained from ATHAM in a bidimensional configuration (distance-altitude). Simulations refer to the volcanic plume after 26 min from the beginning of the eruption.

the ATHAM parameter selection has been accomplished by minimizing the bias between actual observed radar reflectivity and the ATHAM-derived reflectivities. Radar vertical cuts from $1 \mathrm{~h}$ are used for the comparison between actual radar observations and ATHAM simulations. To this goal, PSDs from past eruptions are used as in [26]. It should be mentioned that the validity of the comparison is limited to the radar sensitivity of coarse and larger particles [26]. However, in the proximity of the volcanic vent (i.e., within approximately $50 \mathrm{~km}$ ), larger particles are likely to dominate the radar backscattering signal.

The nearest radiosonde site in Keflavík (station identifier: 04018 BIKF) at 00 UTC, of May 21, 2011, is used to initialize the ATHAM model. For the analyzed simulations, no crosswind effects (the initial horizontal wind component is set to zero) are taken into account while the terrain height is modeled through a Gaussian profile with standard deviation (std) and peak values specified as in Table I. Even though crosswind effects can significantly affect plume structure and microwave BTs, we tried to keep the simulations as simple as possible.

Since the output of ATHAM is provided on a stretched grid (i.e., fine grid spacing near the volcano vent and successively coarser resolution when moving away from the volcano vent to the lateral boundaries of the model domain), we performed a resampling of ATHAM output to obtain it on an evenly spaced grid. This is needed to be able to use ATHAM output as input for SDSU radiative transfer simulator. The final vertical and horizontal grid spacing values of the interpolated 2-D outputs of ATHAM are 0.5 and $0.1 \mathrm{~km}$, respectively.
TABLE I

INPUT PARAMETERS FOR THE ATHAM SIMULATION

\begin{tabular}{l|c|c}
\hline \multicolumn{1}{c|}{ Variable name } & Units & Value \\
\hline Height of the Gaussian vent & {$[\mathrm{km}]$} & 1.4 \\
\hline Width (std) of the Gaussian vent & {$[\mathrm{km}]$} & 60 \\
\hline Height of the Gaussian valley & {$[\mathrm{km}]$} & 0.08 \\
\hline Width (std) of the Gaussian valley & {$[\mathrm{km}]$} & 20 \\
\hline Initial velocity at the vent & {$[\mathrm{m} / \mathrm{s}]$} & 200 \\
\hline Potential temperature at the vent & {$[\mathrm{K}]$} & 813 \\
\hline Specific water vapor concentration & {$[\mathrm{kg} / \mathrm{kg}]$} & 0.090 \\
\hline Specific sulfur dioxide concentration & {$[\mathrm{kg} / \mathrm{kg}]$} & 0.010 \\
\hline Specific cloud water concentration & {$[\mathrm{kg} / \mathrm{kg}]$} & 0 \\
\hline Specific rain concentration & {$[\mathrm{kg} / \mathrm{kg}]$} & 0 \\
\hline Specific cloud ice concentration & {$[\mathrm{kg} / \mathrm{kg}]$} & 0 \\
\hline Specific graupel concentration & {$[\mathrm{kg} / \mathrm{kg}]$} & 0 \\
\hline Specific small lapilli concentration & {$[\mathrm{kg} / \mathrm{kg}]$} & 0.030 \\
\hline Specific large lapilli concentration & {$[\mathrm{kg} / \mathrm{kg}]$} & 0.070 \\
\hline
\end{tabular}

\section{B. Microwave Sensor Response Simulator}

Microwave passive simulations of volcanic plumes are obtained by using SDSU [20]. SDSU is adopted as a forward-model tool in the processes of constructing and testing performances of satellite algorithms for meteorological applications. SDSU is based on the delta-Eddington radiative transfer approximation, including both single and multiple scattering phenomena [29]-[31]. Mie routines for volume-equivalent spherical particles are used to compute the single-scattering optical parameters (extinction, albedo, and asymmetry factor), whereas simulated polarized radiances are 
TABLE II

REFRACTIVE INDEXES OF ASH

\begin{tabular}{l|c}
\hline Freq. & {$[20,190] \mathrm{GHz}$} \\
\hline $\boldsymbol{n}_{A S H^{\prime}}$ & 2.48 \\
$\boldsymbol{n}_{A S H^{\prime \prime}}$ & 0.016 \\
\hline$n_{A S H^{\prime},}, n_{A S H^{\prime}}:$ real and \\
imaginary part of refractive \\
\multicolumn{2}{c}{ index of ash, respectively. }
\end{tabular}

derived using the delta-Eddington solution with polarizationdependent surface conditions. The radiances from space (or antenna equivalent temperatures) are derived by convolving the antenna beam pattern with the simulated scene for a given spaceborne sensor specification. Note that SDSU is a pseudo3-D simulator since radiances are derived from single vertical columns projected along the observation nadir angle (i.e., slant path approximation). SDSU is capable to simulate not only satellite microwave passive sensors but also infrared radiometers and microwave radar [20]. It should be noted that fully 3-D simulations, instead of pseudo-3-D, would be ideal to investigate the impact of the slant path approximation. However, a rigorous treatment would require a significant increase in numerical complexity, requiring the coupling of 3-D ATHAM volcanic plume simulations with a fully 3-D radiative transfer model which is beyond the scope of this paper. For volcanic applications, the input parameters of SDSU are adapted to work with the ATHAM numerical outputs. For convenience, the adapted SDSU version is named SDSU-Ash. In its default configuration, SDSU includes six microphysical species: graupel, hail, rain, cloud water, snow, and cloud ice. They are described in terms of vertical profiles of concentrations $C_{p}$ (in grams per cubic meter) of the respective microphysical species " $p$," complex refractive index $\left(n_{p}\right)$ as a function of wavelength $(\lambda), n_{p}(\lambda)=n_{p}^{\prime}(\lambda)-j n_{p}^{\prime \prime}(\lambda)$, and PSDs $N_{p}(D)$ of spherical particles of equivolume diameter $D$. To adapt SDSU to treat volcanic plumes, two hydrometeors that are unlikely to occur in volcanic plumes are modified to mimic small ash and large lapilli (LL). The values of $C_{p}$ profiles, with $p=$ snow and $p=$ hail in SDSU, have been substituted with profiles of ash from ATHAM: $p=\mathrm{SL}$ and $p=\mathrm{LL}$ for small lapilli (SL) and LL, respectively. $n_{\mathrm{SL}}(\lambda)$ and $n_{\mathrm{LL}}(\lambda)$ are adapted accordingly. The values of $n_{\mathrm{SL}}(\lambda)=n_{\mathrm{LL}}(\lambda)=n_{\mathrm{ash}}(\lambda)$ are listed in Table II [32], [33]. For other species, namely, graupel, rain, cloud water, and cloud ice, a direct correspondence between ATHAM outputs and SDSU-Ash inputs has been assumed. Ash PSDs $N_{p}(D)$ are assumed to follow a Gamma distribution

$$
\begin{aligned}
& N_{p}(D)=N_{n p}\left(\frac{6 \cdot(3.67+\mu)^{\mu+4}}{3.67^{4} \Gamma(\mu+4)}\right)\left(\frac{D}{D_{n p}}\right)^{\mu} \\
& \exp \left[-(3.67+\mu)\left(\frac{D}{D_{n p}}\right)\right]
\end{aligned}
$$

where $N_{n p}$ and $D_{n p}$ are the intercept parameter and the volume-weighted median diameter, respectively, in units of $\mathrm{m}^{-4}$ and $\mathrm{mm}$, whereas $\mu$ is the unitless shape. In SDSU-Ash, the PSD $N_{p}(D)$ is given in $\mathrm{m}^{-4}$.
TABLE III

PSD PARAMETERS For ASH Classes

\begin{tabular}{c|ccc}
\hline PSD param.: & $\begin{array}{c}\boldsymbol{D}_{\boldsymbol{n}} \\
{[\mathrm{mm}]}\end{array}$ & $\begin{array}{c}\boldsymbol{\mu} \\
{[-]}\end{array}$ & $\begin{array}{c}\boldsymbol{\rho}_{\boldsymbol{p}} \\
{\left[\mathrm{kg} \mathrm{m}^{-3}\right]}\end{array}$ \\
\hline Fine Ash & 0.02 & 0.5 & $2.5 \times 10^{-3}$ \\
Coarse Ash & 0.3 & 1.1 & $2.0 \times 10^{-3}$ \\
Small Lapilli & 1.5 & 1.6 & $1.2 \times 10^{-3}$ \\
Large Lapilli & 5.0 & 2.0 & $1.0 \times 10^{-3}$ \\
\hline
\end{tabular}

$D_{n p}, \mu, \rho_{p}:$ median diameter, shape parameter and concentration of Particle type " $p$ "

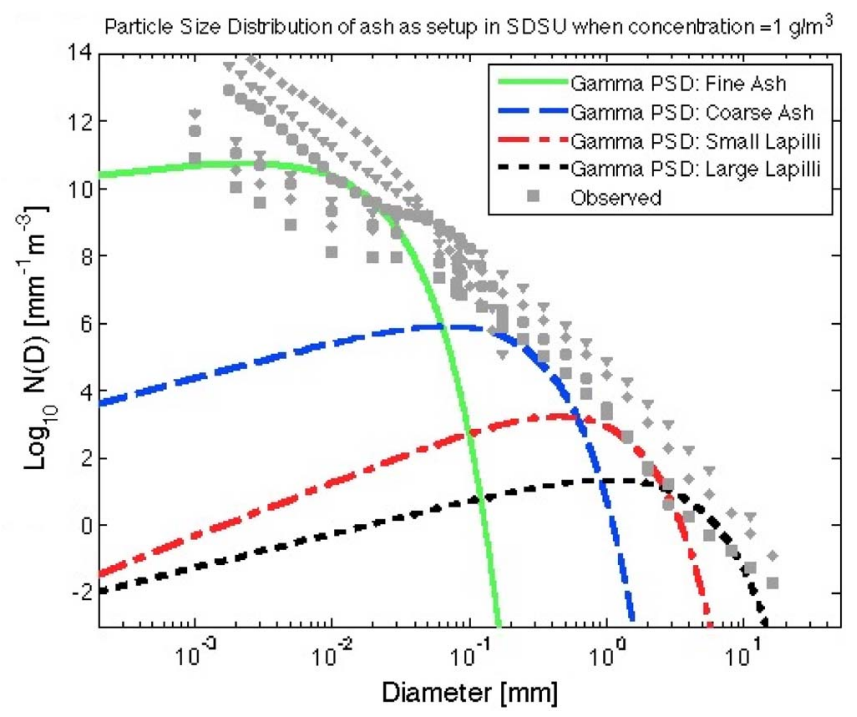

Fig. 3. PSDs for volcanic ash. Gray markers refer to surface data, collected after the Grímsvötn volcanic eruption in 2004 [7], [8]. PSD gamma model curves, given in (1) in the main text, are indicated by dotted and continuous lines with parameters listed in Table III. The units of $N_{p}(D)$ are in $\mathrm{mm}^{-1} \cdot \mathrm{m}^{-3}$ since it is a more conventional choice for radar studies.

While $D_{n p}$ and $\mu$ are fixed, $N_{n p}$ is calculated from the knowledge of concentrations $C_{p}$ and density $\left(\rho_{p}\right)$ in kilograms per cubic meter through [26]

$$
N_{n p}=\frac{C_{p} 10^{-3}}{\pi \rho_{p}}\left(\frac{3.67}{D_{n p} 10^{-3}}\right)^{4}
$$

To be consistent with the ATHAM output, SL and LL PSDs have been assumed in SDSU-Ash for describing the ash classes. Their parameters are listed in Table III, together with two additional ash classes, namely, FA and coarse ash (CA), which are shown in Fig. 3. CA and FA complete the description of the observed PSD for small particle sizes. In this figure, the overall agreement of $N_{p}(D)$ in (1) and PSD parameters from Table III with in situ PSD retrievals, relative to the 2004 Grímsvötn eruption [7], [8], is shown for the case of $C_{p}=1 \mathrm{~g} / \mathrm{m}^{3}$. The measured PSD is derived from ash deposits collected close to the volcano vent (up to $60 \mathrm{~km}$ away) and within a few years after the eruption. Consequently, FA fraction of the erupted tephra may be underestimated. However, this does not affect simulated radar reflectivities since FA barely affects microwave radiation. Two additional assumptions are made when using PSD ground measurements of tephra. The first assumption is that the PSD measured at the ground is representative of the PSD at the vent. The second assumption is that the sampling of PSD 

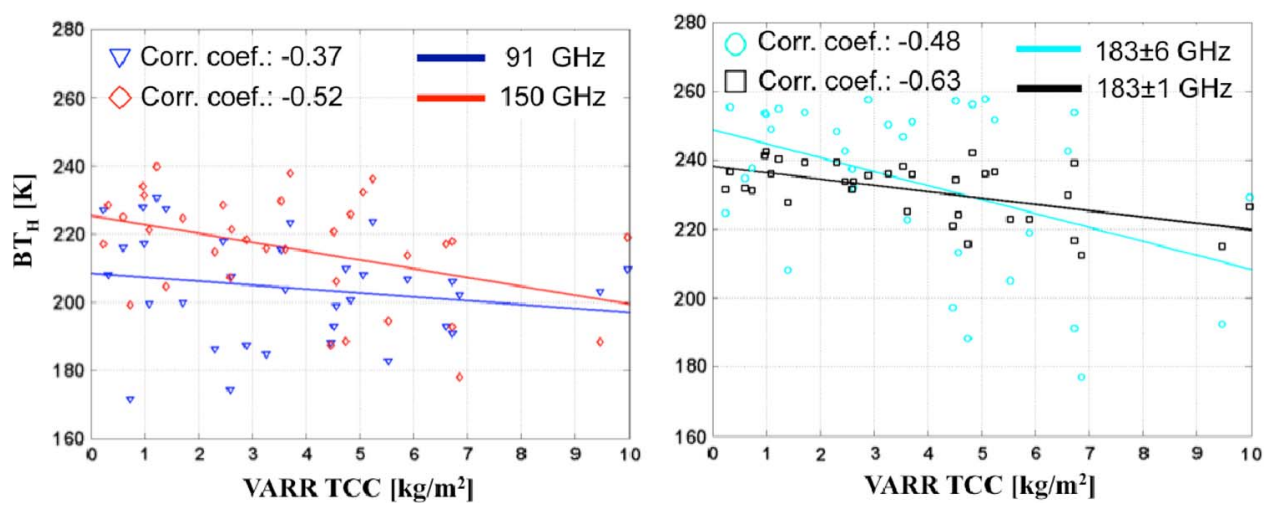

Fig. 4. Measured brightness temperature in horizontal polarization over land $\mathrm{BT}_{H}$ (in Kelvin) from SSMIS versus the TCC in kilograms per square meter retrieved from ground-based C-band radar data. Four frequency channels from SSMIS are considered, as specified in the legend of each panel. The tilted lines indicate the linear regressions on the measured data points. The SSMIS data are taken at 08:34 UTC on May 22 for the Grímsvötn eruption. The radar acquisition is taken at 08:35 UTC of the same day. Radar and SSMIS data have been collocated, as explained in the main text. The symbolism $f \pm x$ GHz, where $f$ is the central frequency, refers to the received $\mathrm{BT}_{H}$ in the interval $f-x$ and $f+x \mathrm{GHz}$. The (Corr. coef.) cross-correlation coefficients between $\mathrm{BT}_{H}$ and $T C C$ data points are shown in the legend as well.

done after the eruption is still representative of what happened during the eruption itself. The last assumption is generally met in Iceland due to the snow cover preserving the deposited tephra.

\section{RESUlts}

In this section, results are discussed in terms of microwave observations and their correlation with SDSU-Ash numerical simulations. Observations include microwave ground weather C-band radar estimates and SSMIS satellite passive measurements for the 2011 Grímsvötn eruption, as shown in Fig. 1. The simulation results are produced from the coupled ATHAM plus SDSU-Ash forward-model simulator with the aim to demonstrate the consistency between simulation and observational data. ATHAM coupled with SDSU-Ash is used to correlate brightness temperatures from satellite microwave radiometer and columnar ash concentrations of the scene. Thus, our goal is not to reproduce the space-time evolution of volcanic plume with the ATHAM model but to provide a simulation that, when coupled with a radiative transfer model, can provide statistically consistent data for the interpretation of available radiometer observations.

\section{A. Multisensor Intercomparison of Microwave Observations}

Ground-based measurements at the surface are usually taken as a reference for remote sensing (e.g., [7]). For the 2011 Grímsvötn eruption case study, ground ash samples and drills were not available. Hence, ground-based radar data are considered as a relatively good source for comparisons with spaceborne SSMIS brightness temperature measurements. Indeed, the comparisons between the ground-based microwave radar and space-based remote sensing responses are more consistent with each other than when they are individually compared with ash deposits. This is because satellite and radar products are both instantaneous and areal measurements of airborne phenomena and are thus substantially different from ash deposits collected at ground, which are time- integrated measurements at a given point after the eruption phase.

We have plotted SSMIS and observed radar data in Fig. 1, in order to provide a first attempt to qualitatively relate horizontally polarized microwave $\mathrm{BT}_{H}$ with measured copolar radar reflectivity $Z_{H m}$. For a direct comparison of ground-based radar and satellite radiometer observations, it is necessary to spatially average the measured radar reflectivity to the SSMIS footprint, which is approximately $13 \times 16 \mathrm{~km}^{2}$ for frequencies above $90 \mathrm{GHz}$ [34]. This means that the horizontal maps of radar acquisitions have been further filtered to a lower resolution of $14 \times 14 \mathrm{~km}^{2}$ from the available resolution of $2 \times 2 \mathrm{~km}^{2}$. Subsequently, after the collocation of the radar grid points with those from SSMIS $\mathrm{BT}_{H}$, the instantaneous values of radar-derived particle concentration, expressed in kilograms per cubic meter, have been retrieved applying the VARR technique. The latter has been applied to each radar vertical profile, and then, vertical integration has been performed to obtain the total columnar content (TCC), expressed in kilograms per square meter. It is worth noting that a reconstruction of the radar vertical profiles has been applied before performing the vertical integrals. We extrapolated the vertical profile of reflectivity down to the surface, assuming a constant value that is equal to the lowest altitude measurement of reflectivity [35].

The result of this quantitative comparison is shown in Fig. 4, where the horizontal extension of the volcanic cloud was defined as the area where the values of VARR TCC are greater than zero. Resolution of VARR TCC has been degraded to match the resolution of satellite observations. This results in 34 data points that were used to compute a linear fit and correlation coefficient. The lowest available value for VARR TCC was $0.2 \mathrm{~kg} / \mathrm{m}^{2}$, and thus, the linear regressions in Fig. 4 are only strictly valid above this value, although they were extrapolated to $T C C=0$. Since our focus is the analysis of $\mathrm{BT}_{H}$ measurements in the presence of ash (i.e., TCC $>0$ ), this extrapolation is acceptable, even though it may become inaccurate close to $T C C=0$. From Fig. 4 , there is an evident correlation between radar-derived TCC and satellite SSMIS $\mathrm{BT}_{H}$ values (above $90 \mathrm{GHz}$ ), extracted from the data matching 
TABLE IV

BT $_{H}$ Versus TCC REgRESSION PARAMETERs From OBSERVATIONS

\begin{tabular}{c|cc}
\hline$B T_{\text {Hlnd }}=a \cdot(T C C)+b, T C C\left[\mathrm{~kg} / \mathrm{m}^{2}\right] ;$ & $B T_{\text {Hlnd }}[\mathrm{K}]$ \\
\hline Freq. [GHz] & $\begin{array}{c}a \\
{\left[\mathrm{~m}^{2} \mathrm{~K} / \mathrm{kg}\right]}\end{array}$ & $\begin{array}{c}b \\
{[\mathrm{~K}]}\end{array}$ \\
\hline $\mathbf{9 1}$ & -1.5 & 210 \\
$\mathbf{1 5 0}$ & -2.5 & 225 \\
$\mathbf{1 8 3} \pm \mathbf{1}$ & -1.9 & 239 \\
$\mathbf{1 8 3} \pm \mathbf{6}$ & -3.9 & 249 \\
\hline
\end{tabular}

$B T_{\text {Hind }}$ : Brightness temperature over land; $T C C$ : Total Columnar Content

in Fig. 1 over land [Fig. 1(c)-(e), (g), and (h)]. The correlation coefficients of $\mathrm{BT}_{H}$ at 91 and $150 \mathrm{GHz}$ (left panel), and 183 \pm 6 and $183 \pm 1 \mathrm{GHz}$ (right panel) with TCC are -0.37 , $-0.52,-0.48$, and -0.63 , respectively. The relatively high correlation between $T C C$ and the water vapor absorbing channels around $183 \mathrm{GHz}$ is due to high clear-air opacity and surface insensitivity. The absolute value of the correlation coefficient increases from 91 to $183 \pm 1 \mathrm{GHz}$ except for $183 \pm 6 \mathrm{GHz}$. The channel at $183 \pm 6 \mathrm{GHz}$ is more influenced by the water vapor at lower levels than that at $183 \pm 1 \mathrm{GHz}$. The correlation at $183 \pm 6 \mathrm{GHz}$ decreases presumably due to the sensitivity to tropospheric humidity, which has larger variability than that at higher levels, and it is decoupled from the ash content. However, the $183 \pm 6-\mathrm{GHz}$ channel cannot be defined neither lower nor higher frequency than $183 \pm 1 \mathrm{GHz}$; it just covers a larger dual-side frequency band. This also helps to explain why the absolute value of the correlation of $T C C$ and $\mathrm{BT}_{H}$ at $183 \pm 6 \mathrm{GHz}$ decreases with respect to the neighbor channels. Table IV lists the regression coefficients of the empirical linear model in Fig. 4. This result offers the potential to estimate the columnar ash concentration from $\mathrm{BT}_{H}$ once ash regions have been identified.

\section{B. Self-Consistency of Microwave Radiance Simulations}

In this section, the analysis of the space-based microwave radiometric signatures of a volcanic plume is shown in terms of its consistency with the coupled forward-model SDSU-Ash mentioned previously. The considered radiometric instrument for the numerical simulations is the SSMIS. This leads to a straightforward comparison with the observations previously discussed. Our goal here is not to reproduce the observed signature of the SSMI scene using SDSU-Ash (as it would require specific knowledge of several geophysical and atmospheric parameters) but a self-consistency analysis, i.e., the correlation and dynamic range of the $\mathrm{SSMI} \mathrm{BT}_{H}$ channels with the columnar ash concentration.

Simulations of $\mathrm{BT}_{H}$ from the synthetic scenario, shown in Fig. 2, have been generated using SDSU-Ash. The assumed refractive indexes for ash are listed in Table II. The PSDs are fixed to those that correspond to SL and LL (Table III) since they provided the best result in reproducing the observed correlation signatures (as it will be shown later). In addition, it seems plausible to have larger grain size as a lapilli-type PSD near the volcanic source of an event as big as the 2011 Grímsvötn eruption [37]. Fig. 5 shows the microwave brightness temperature at horizontal polarization over land $\left(\mathrm{BT}_{H}\right)$

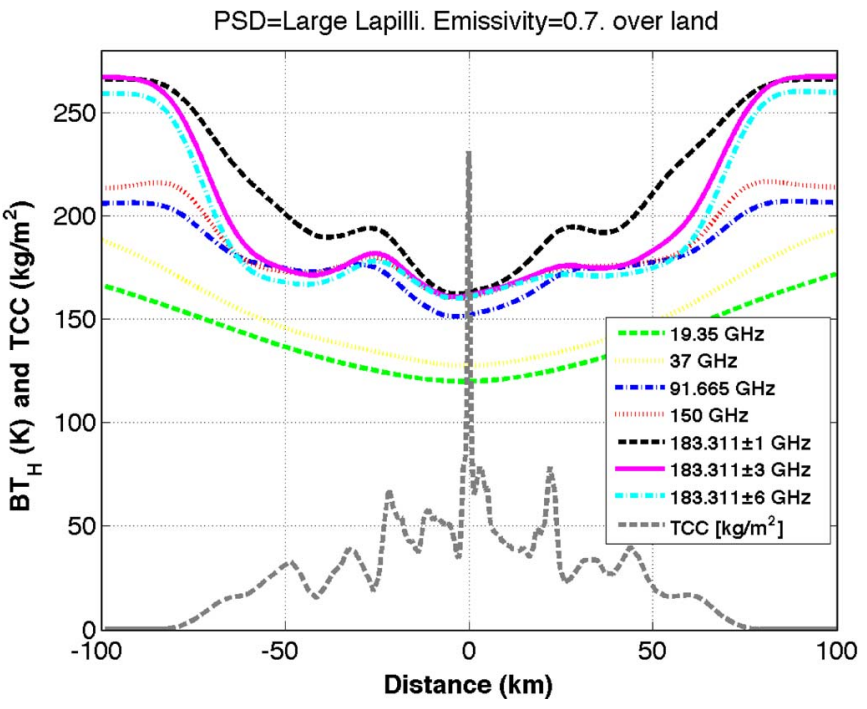

Fig. 5. Simulated brightness temperatures in horizontal polarization over land $\left(\mathrm{BT}_{H}\right)$, for frequency channels as specified in the legend, versus the distance from the volcano vent for the reference 2-D-ATHAM synthetic plume shown in Fig. 2. $\mathrm{BT}_{H}$ calculations have been done using the SDSU-Ash (satellite data sensor unit simulator for ash). The gray curve shows the ATHAM synthetic $T C C$ in kilograms per square meter.

when the radiometer's field of view intercepts the volcanic plume. Properties of the corresponding plume are shown in Fig. 2. The terrain emissivity, fixed here to 0.7 , is difficult to estimate. It depends on the type of surface vegetation and coverage (e.g., snow and sand). In the microwave regime, a terrain average emissivity of 0.9 is usually assumed in the absence of snow [38]. During the 2011 Grímsvötn eruption, snow was present on the ground, which implies lower values for the terrain emissivity. As discussed hereinafter, sensitivity tests confirm that a terrain emissivity of 0.7 is a reasonable choice in our case. In Fig. 5, a depression in $\mathrm{BT}_{H}$ can be noted near the volcanic vent. This phenomenon has already been observed before [10] and can be explained by the simultaneous presence of high ash and ice concentrations near the vent, causing enhanced extinction of upwelling radiation from the ground.

Sensitivity tests with respect to PSD parameters listed in Table III and terrain emissivity were also performed by determining the maximum values of $\mathrm{BT}_{H}$ and the difference between maximum and minimum values of $\mathrm{BT}_{H}$, named $\mathrm{MBT}_{H}$ and $\mathrm{DBT}_{H}$, respectively. Values for $\mathrm{MBT}_{H}$ are found to decrease or remain constant as the PSD varies from FA to LL with lower frequencies being more sensitive to PSD parameters than higher frequencies. The variations of $\mathrm{MBT}_{H}$ can be as large as $30 \mathrm{~K}$ at $19 \mathrm{GHz}$ and less than $1 \mathrm{~K}$ at $183 \pm 6 \mathrm{GHz}$. The difference quantity $\mathrm{DBT}_{H}$ is a measure of the extinction effects induced by the volcanic cloud. $\mathrm{DBT}_{H}$ increases as particle size increases for frequencies below $37 \mathrm{GHz}$ with differences up to $60 \mathrm{~K}$. For frequencies greater than $37 \mathrm{GHz}$, no clear trend of $\mathrm{DBT}_{H}$ as a function of particle size is observed, potentially because Mie scattering becomes size independent at higher frequencies. In this case, variations in $\mathrm{DBT}_{H}$ of up to $45 \mathrm{~K}$ are found.

Considering the larger dynamic range of $\mathrm{BT}_{H}$ for channels above $90 \mathrm{GHz}$ (see Fig. 1), together with their better spatial 


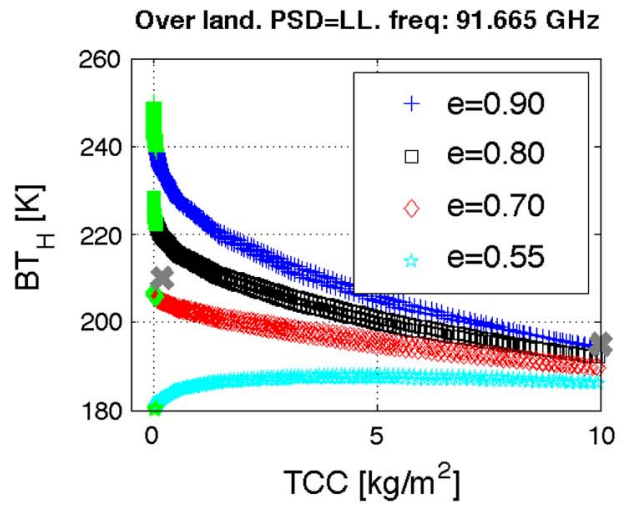

Over land. PSD=LL. freq: $183.311 \pm 1 \mathrm{GHz}$

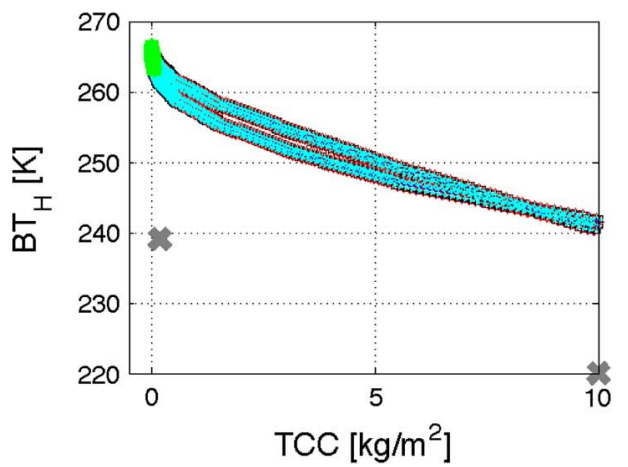

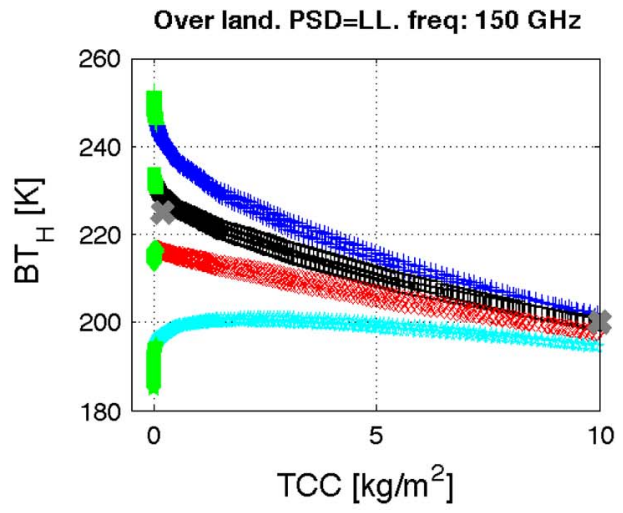

Over land. PSD=LL. freq:183.311 $\pm 6 \mathrm{GHz}$

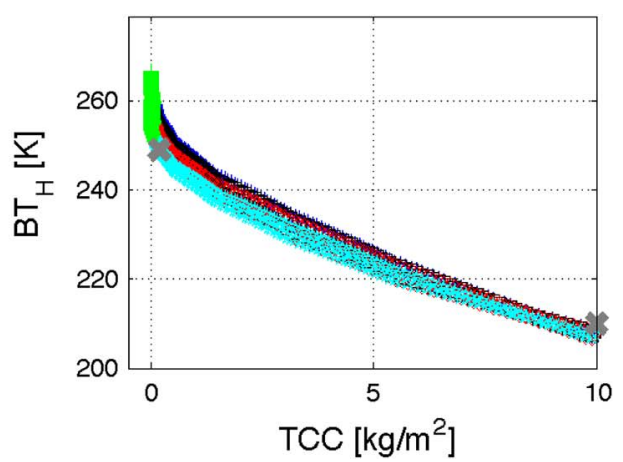

Fig. 6. Simulated brightness temperatures at horizontal polarization over land $\left(\mathrm{BT}_{H}\right)$, for frequency channels as specified in the title of each panel and terrain emissivity (e), as listed in the legend, versus the synthetic TCC in kilograms per square meter from the 2-D-ATHAM and SDSU-Ash (satellite data sensor unit simulator for ash) simulations. The gray crosses refer to the extremes of the linear regressions, as derived from the SSMIS and radar observations shown in Fig. 4. The symbolism $f \pm x \mathrm{GHz}$, where $f$ is the central frequency, refers to the received radiation in the interval $f-x$ and $f+x$ GHz. The green-colored points on the left side in each panel refer to areas of the ATHAM simulation far from the volcanic plume shown in Fig. 2.

TABLE V

$\mathrm{BT}_{H}$ Versus TCC REgRESSiOn PARAmeters From Simulations

\begin{tabular}{c|cccc}
\hline \multicolumn{5}{c}{$B T_{H \ln d}=a \cdot(T C C)+b, T C C\left[\mathrm{~kg} / \mathrm{m}^{2}\right] ; B T_{H \operatorname{lnd}}[\mathrm{K}]$} \\
\hline FREQ. [GHZ] & $\boldsymbol{e}=\mathbf{0 . 5 5}$ & $\boldsymbol{e}=\mathbf{0 . 7 0}$ & $\boldsymbol{e}=\mathbf{0 . 8}$ & $\boldsymbol{e}=\mathbf{0 . 9}$ \\
& $\boldsymbol{a} / \boldsymbol{b}$ & $\boldsymbol{a} / \boldsymbol{b}$ & $\boldsymbol{a} / \boldsymbol{b}$ & $\boldsymbol{a} / \boldsymbol{b}$ \\
\hline $\mathbf{9 1}$ & $0.3 / 186$ & $-1.7 / 205$ & $-3.0 / 218$ & $4.4 / 231$ \\
$\mathbf{1 5 0}$ & $-0.4 / 201$ & $-2.1 / 218$ & $-3.2 / 229$ & $-4.3 / 239$ \\
$\mathbf{1 8 3} \pm \mathbf{1}$ & $-2.3 / 261$ & $-2.3 / 261$ & $-2.3 / 261$ & $-2.3 / 261$ \\
$\mathbf{1 8 3} \pm \mathbf{6}$ & $-4.7 / 249$ & $-4.9 / 251$ & $-5.0 / 252$ & $-5.7 / 253$ \\
\hline
\end{tabular}

$B T_{\text {Hlnd }}$ : Brightness temperature in horizontal polarization over land; TCC: Total Columnar Content.

resolution than those below $90 \mathrm{GHz}$, the correlation between the simulated $\mathrm{BT}_{H}$ at $91.6,150.0,183 \pm 1$, and $183 \pm 6 \mathrm{GHz}$ and the TCC of the simulated volcanic plume is calculated.

Trends of $\mathrm{BT}_{H}$ with $T C C$ are shown in Fig. 6 for values of terrain emissivity $(e)$ between 0.55 and 0.90 . The effects of the terrain emissivity are relevant at 91 and $150 \mathrm{GHz}$, whereas they are less influential for frequencies close to the water vapor absorption peak (i.e., $183 \mathrm{GHz}$ ) as evident in the small variations of $\mathrm{BT}_{H}$ as a function of $e$ at those frequencies.

In Fig. 6, the values of $\mathrm{BT}_{H}$, where TCC approaches zero, refer to the areas of the ATHAM simulation far away from the volcanic plume. In these areas, the absorption of water vapor drives the $\mathrm{BT}_{H}$ response. Excluding these areas from the analysis (marked as green), Table $\mathrm{V}$ lists the linear regression coefficients of $\mathrm{BT}_{H}$ as a function of TCC.
Comparing values from Tables IV and V demonstrates the agreement between SDSU-Ash simulations and SSMIS observations. For visualization, the extreme points of the linear regressions derived from the measurements shown in Fig. 4 are marked with couples of gray crosses in each panel of Fig. 6. The agreement between SSMIS observations and SDSUAsh simulations is good in terms of bias and slope. A terrain emissivity between 0.7 and 0.8 best explains the behavior of $\mathrm{BT}_{H}$ for most of the considered channels. The only exception is the channel at $183 \pm 1 \mathrm{GHz}$, where the simulation strongly overestimates observational estimates. Terrain emissivities in the range of $[0.7,0.8]$ are consistent with ice covered and poorly vegetated terrain, as expected in Iceland during spring [11]. To explain the anomalous behavior of $\mathrm{BT}_{H}$ as a function of $T C C$ at $183 \pm 1 \mathrm{GHz}$ in Fig. 6, we have varied the water vapor and the ice content along the whole profile in our synthetic data. Results are shown in Figs. 7 and 8 in the form of linear regression curves. A strong reduction of water vapor (between $7 \%$ and $25 \%)$ produces better agreement between measurements and simulations at $183 \pm 1 \mathrm{GHz}$ at the cost of a larger disagreement at other channels. On the other hand, the variations in ice content produce a negligible effect at $183 \pm 1 \mathrm{GHz}$, whereas they have a big impact at 150 and $183 \pm 6 \mathrm{GHz}$, particularly for larger values of TCC. To investigate this further, we simulated additional scenarios by varying temperatures between simulated and radiosonde observed profiles and by reducing the water vapor profile successively from above, instead of reducing 


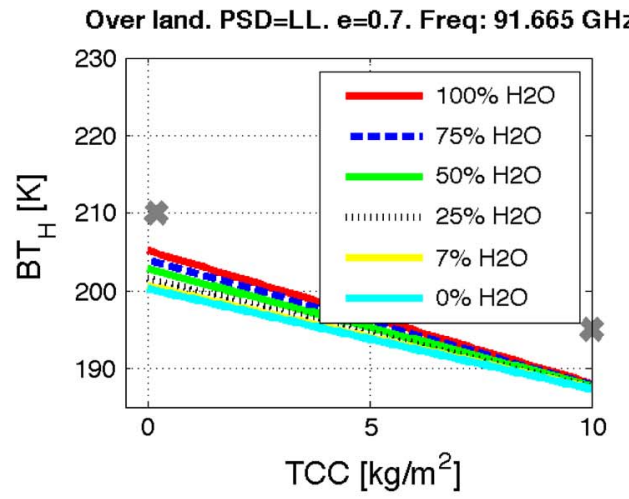

Over land. PSD=LL. e=0.7. Freq: $183.311 \pm 1 \mathrm{GHz}$

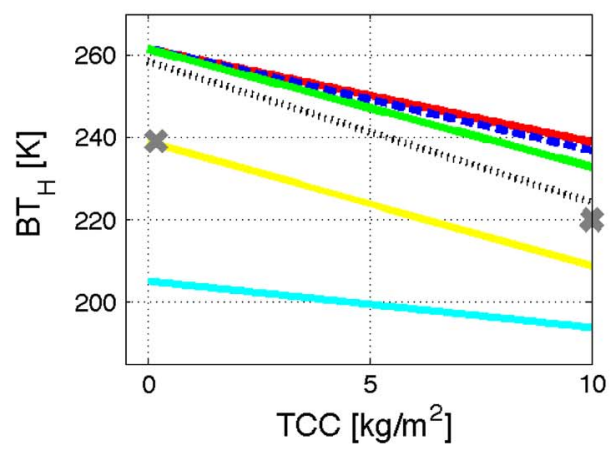

Over land. $\mathrm{PSD}=\mathrm{LL}$. $\mathrm{e}=0.7$. Freq: $150 \mathrm{GHz}$

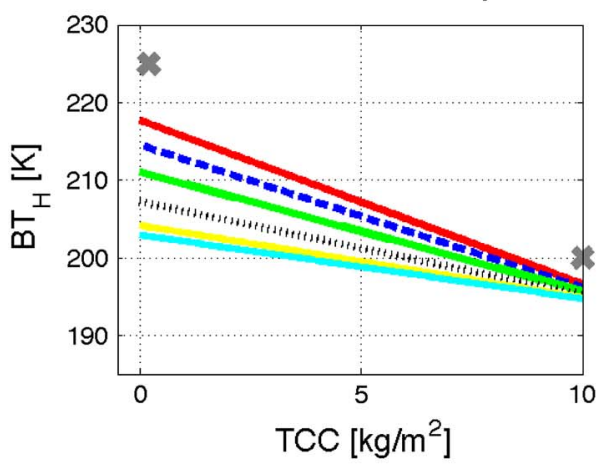

Over land. PSD=LL. e=0.7. Freq: $183.311 \pm 6 \mathrm{GHz}$

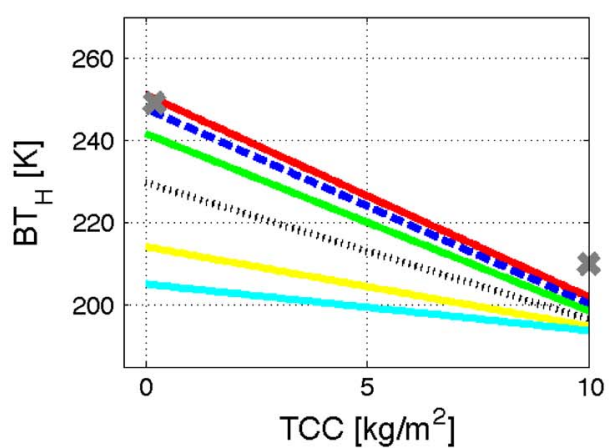

Fig. 7. As in Fig. 6, but varying the water vapor content as shown in the legend and considering, for simplicity, the linear regression curves (instead of the simulated dots).

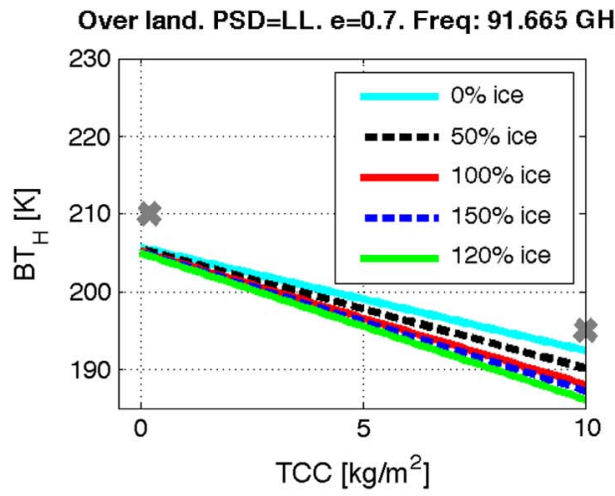

Over land. $\mathrm{PSD}=\mathrm{LL} . \mathrm{e}=\mathbf{0} .7$. Freq: $183.311 \pm 1 \mathrm{GHz}$

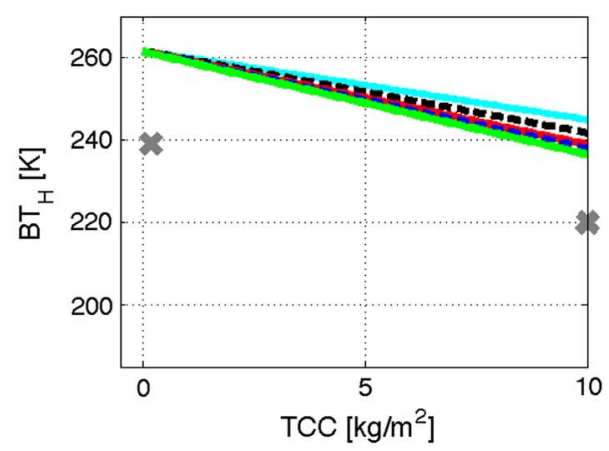

Fig. 8. As in Fig. 7, but varying the ice content as shown in the legend.

it along the whole profile. The result of this exercise is shown in Fig. 9. When the temperature profiles from ATHAM output are used (left panel), we found that progressive cuts of water vapor do not improve the comparison with measured quantities

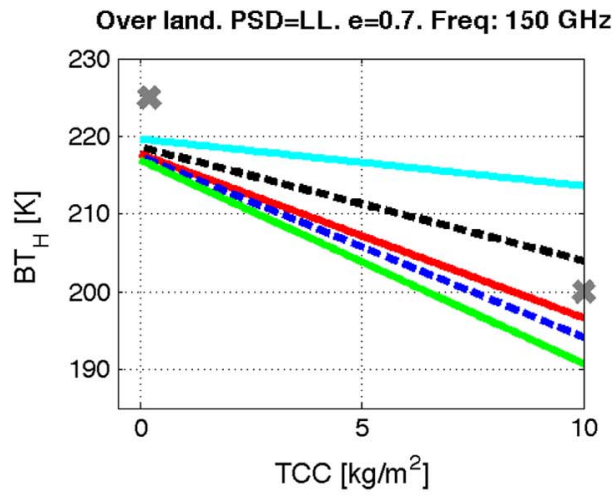

Over land. $P S D=L L . ~ e=0.7$. Freq: $183.311 \pm 6 \mathrm{GHz}$

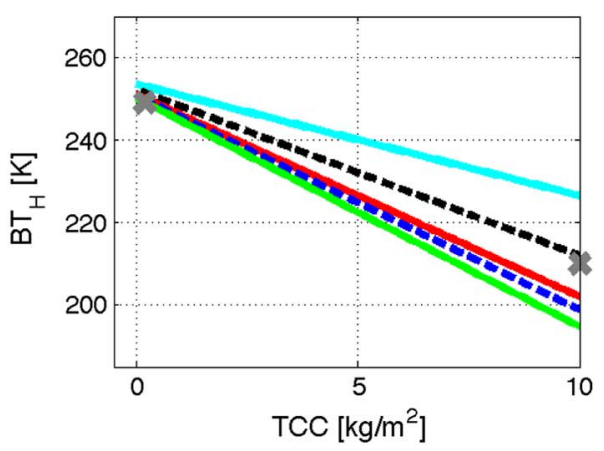

even though the simulated $\mathrm{BT}_{H}$ curves at $183 \pm 1 \mathrm{GHz}$ change with respect to that shown in Fig. 6 (lower left panel). They tend to decrease at higher TCC, but they do not show the same behavior in clear air, i.e., for $T C C$ values close to zero. We 

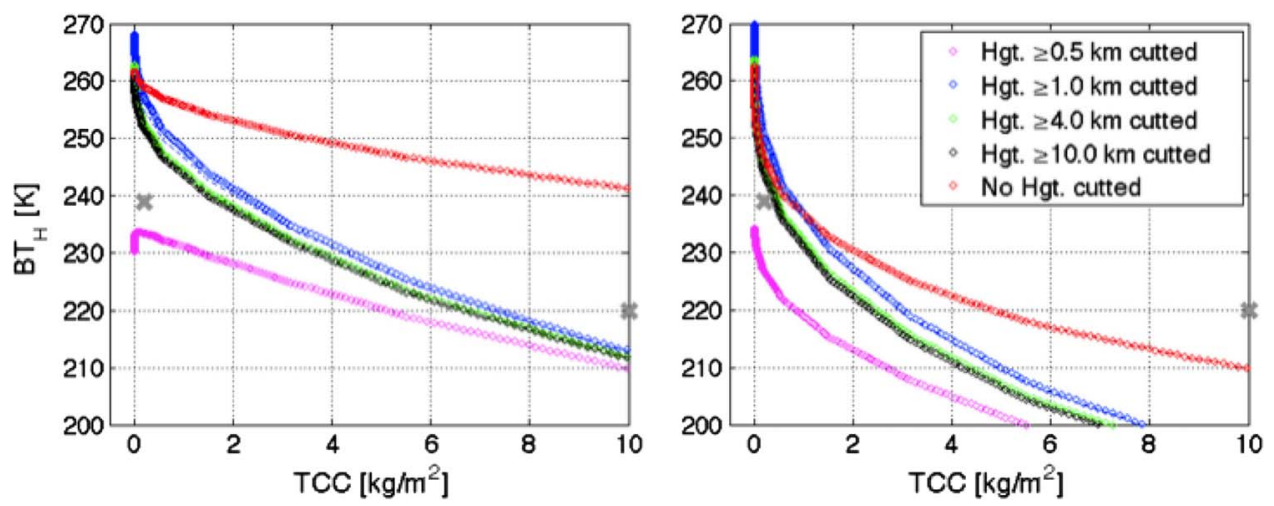

Fig. 9. Radiative transfer simulations of brightness temperature at horizontal polarization $\left(\mathrm{BT}_{H}\right)$ (in Kelvin) at $183 \pm 1 \mathrm{GHz}$ when the temperature profiles from ATHAM (left) and the radiosonde (right) are applied in the SDSU radiative model. The gray markers refer to the linear regression performed on measured data. Different colors show the simulation scenarios that we obtained cutting the water vapor profiles progressively from above, as indicated in the legend of the figure.

repeated the same exercise as before, considering the profiles of temperature from the nearest radiosonde (RAOB: 04018 BIKF Keflavikurflugvollur Observations at 00Z May 21, 2011, approximately $260 \mathrm{~km}$ away from the volcano) instead of those given by ATHAM 2-D simulation output. In this case (shown in the right panel of Fig. 9), we observed a significant decrease of $\mathrm{BT}_{H}$ for values of $T C C$ less than $0.5 \mathrm{~kg} / \mathrm{m}^{2}$. However, for values larger than $T C C=0.5 \mathrm{~kg} / \mathrm{m}^{2}$, the $\mathrm{BT}_{H}$ curves continue to smoothly decrease. In this case, the difference between simulated $\mathrm{BT}_{H}$ values and those derived from measurements is more consistent: about $10 \mathrm{~K}$ for $T C C=10 \mathrm{~kg} / \mathrm{m}^{2}$ and $5 \mathrm{~K}$ for $T C C=0.2 \mathrm{~kg} / \mathrm{m}^{2}$. The analysis shows that the temperature profile plays an important role in the matching simulations and satellite observations at $183 \pm 1 \mathrm{GHz}$. In conclusion, it seems that the temperature and water vapor profile field from the ATHAM output that we used, although consistent with the physics of the problem and with the other physical variables, may not be fully representative of the actual temperature and humidity field. This may be probably due to the Cartesian nature of the ATHAM simulation used.

The forward-model SDSU-Ash can be used to investigate the potential of plume height estimation from the SSMISlike satellite platforms. Even though the plume height is well detected by ground-based microwave radars (e.g., [7]), the support of external information as provided by satellite microwave radiometers can contribute to reduce the estimation uncertainty of this parameters despite the low temporal sampling rate of LEO platforms. Fig. 10 shows the correlation between the ATHAM-derived plume height $(h)$ and $\mathrm{BT}_{H}$ at $183 \pm$ $1 \mathrm{GHz}$, the latter derived from the SDSU-Ash simulations. The choice of other channels does not provide large variations in the results. Consistently with the experiments shown in Fig. 9, two different sixth-order polynomial regressions are shown in Fig. 10. The gray curve refers to the polynomial regression when the ATHAM-derived temperature profiles are used in the radiative transfer calculations. The red dotted curve is obtained considering the simulation that uses the observed temperature profile from the radiosonde instead. At $183 \pm$ $1 \mathrm{GHz}$, the minimum value for $\mathrm{BT}_{H}$ is $212.2 \mathrm{~K}$. This leads to a plume height between 17 and $20 \mathrm{~km}$, depending on which polynomial regression is applied. However, both estimates of

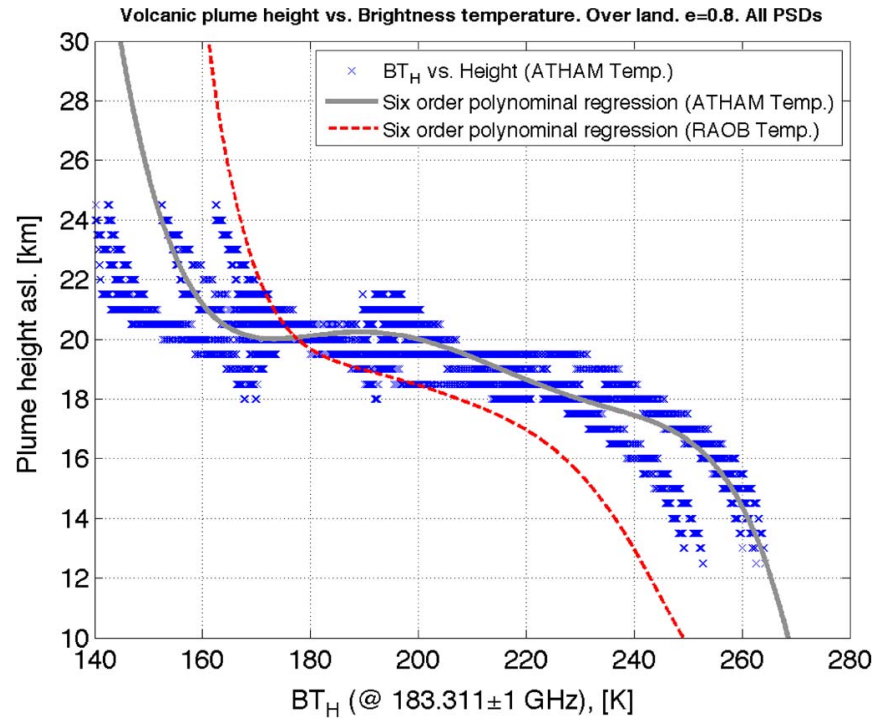

Fig. 10. Simulated correlation between SSMIS brightness temperature at horizontal polarization $\left(\mathrm{BT}_{H}\right)$ over land and the plume height using the SDSU-Ash (satellite data sensor unit simulator for ash). The gray curve shows a six-order polynomial regression when the temperature profiles from ATHAM are considered. The red curve shows the six-order polynomial regression when temperature profiles from radiosonde (RAOB) are considered.

plume height overestimate the 14-km height derived from the ground radar observation at the same time [see Fig. 1(b)], although the $17-\mathrm{km}$ height derived using the observed profiles of temperature is closer to the radar observations. The discrepancy between the ground radar and the space radiometer estimates may be explained by the different sensitivity of the two sensors at different wavelengths, i.e., $5 \mathrm{~cm}$ for the C-band ground-based radar and $0.16 \mathrm{~cm}$ for the SSMIS channel at $183 \mathrm{GHz}$, respectively. It is well established that microwave weather radars are sensible to the presence of CA and lapilli particles [7]. The upper part of the volcanic plume (also called umbrella region) is the cloud portion where the density of the surrounding air equals that of the rising plume, but the plume continues to rise and spread, owing to its momentum and crosswinds, respectively. The volcanic umbrella is usually characterized by FA particles with possible coexistence of and aggregation with ice particles. Smaller particles in the 
umbrella region will lie outside the sensitivity of the C-band radar so that it will lead to an underestimate of the plume height compared to satellite millimeter-wave radiances. In this respect, the complementary information provided by satellite microwave radiometers and ground-based weather radar estimates can be used to better constrain the volcanic cloud height.

\section{CONCLUSION}

A preliminary microwave multisensor analysis of volcanic plumes has been accomplished by combining active and passive measurements with model simulations. The ATHAM and the SDSU radiative transfer model are coupled after some adjustments to ingest volcanic plumes (instead of water clouds) into SDSU. The main conclusions are as follows: 1) The ATHAM/SDSU-Ash models provide results that are consistent with the SSMIS observations in all wavelengths except for $183 \pm 1 \mathrm{GHz}$ where the 2-D Cartesian version of ATHAM produces temperature and humidity profiles that are inconsistent with the observed radiosonde profiles; 2) the modeldriven estimator of plume height provides results consistent with observations even though its accuracy is subject to model uncertainty. These results support the conclusion that it is, in principle, possible to estimate the TCC of an ash cloud near the volcano source vent from a multifrequency measurement of the satellite brightness temperature over land at horizontal polarization. For the 2011 Grímsvötn case study, this hypothesis is proven using the available C-band ground-based radar retrievals and SDSU-Ash model simulations. The sensitivity of SSMIS brightness temperature measurements and ash TCC with respect to volcanic plume water vapor, ice content, and surface background has been also investigated. The results show a good agreement between simulations and measurements. This consistency is particularly evident for SSMIS channels above $90 \mathrm{GHz}$. However, it must be acknowledged that the ash cloud simulation capability is not as mature as for clouds and precipitation, particularly with respect to the knowledge of ash refractive indices and size distributions.

In addition, the capability to estimate plume height near the volcanic vent based on measured brightness temperatures can improve estimates derived from the ground radar. Volcanic plumes are composed of several scatterers, not just ash, with different properties. The combination of multifrequency satellite and ground-based retrievals can help to better sample ash particle spectra. In this context, satellite infrared retrievals of plume height can also be used to infer size information of very fine ash particles, improving the ground-based radar estimates that, in contrast, are not sensitive to the smallest ash particles.

Future developments will focus on increasing the number of case studies for which spaceborne microwave radiometer imagery is available. So far, this research is limited by the small number of events and the sparse sampling of LEO satellite platforms. In addition, a set of ATHAM simulations, instead of a single realization, will be used to consolidate the results shown and to understand the sensitivity limits of space-based microwave radiometers to ash particles. SDSU-Ash simulations will be extended to infrared wavelengths to investigate the potential synergy with spaceborne microwave radiometers for near-source volcanic parameter estimation.

\section{ACKNOWLEDGMENT}

The authors would like to thank P. Pagliara and G. Vulpiani of the Italian Department of Civil Protection and S. Karlsdóttir and B. Palmason of the Iceland Meteorological Office for providing and assisting in reading the C-band radar data.

\section{REFERENCES}

[1] A. J. Prata, I. J. Barton, R. W. Johnson, K. Kamo, and J. Kingwell, "Hazard from volcanic ash," Nature, vol. 354, no. 6348, p. 25, Nov. 1991.

[2] A. Tupper, I. Itikarai, M. S. Richards, F. Prata, S. Carn, and D. Rosenfeld, "Facing the challenges of the international airways volcano watch: The 2004/05 eruptions of Manam, Papua New Guinea," Weather Forecast., vol. 22, no. 1, pp. 175-191, Feb. 2007

[3] A. Folch, A. Costa, and G. Macedonio, "FALL3D: A computational model for transport and deposition of volcanic ash," Comput. Geosci., vol. 35, no. 6, pp. 1334-1342, Jun. 2009.

[4] S. Wen and W. I. Rose, "Retrieval of sizes and total masses of particles in volcanic clouds using AVHRR bands 4 and 5," J. Geophys. Res., vol. 99, no. D3, pp. 5421-5431, Mar. 1994.

[5] G. Gangale, A. J. Prata, and L. Clarisse, "The infrared spectral signature of volcanic ash determined from high-spectral resolution satellite measurements," Remote Sens. Environ., vol. 114, no. 2, pp. 414-425, Feb. 2010.

[6] R. S. J. Sparks, M. I. Bursik, S. N. Carey, J. S. Gilbert, L. Glaze, H. Sigurðsson, and A. W. Woods, Volcanic Plumes. New York, NY, USA: Wiley, 1997.

[7] F. S. Marzano, M. Lamantea, M. Montopoli, B. Oddsson, and M. T. Gudmundsson, "Validating sub-glacial volcanic eruption using ground-based C-band radar imagery," IEEE Trans. Geosci. Remote. Sens., vol. 50, no. 4, pp. 1266-1282, Apr. 2012.

[8] B. Oddsson, "The Grímsvötn eruption in 2004: Dispersal and total mass of tephra and comparison with plume transport models," M.S. thesis, Faculty Sci., Dept. Phys., Univ. Iceland, Reykjavík, Iceland, 2007.

[9] F. S. Marzano, A. Mugnai, G. Panegrossi, M. Pierdicca, E. A. Smith, and J. Turk, "Bayesian estimation of precipitating cloud parameters from combined measurements of spaceborne microwave radiometer and radar," IEEE Trans. Geosci. Remote Sens., vol. 37, no. 1, pp. 596-613, Jan. 1999.

[10] D. J. Delene, W. I. Rose, and N. C. Grody, "Remote sensing of volcanic clouds using special sensor microwave imager data," J. Geophys. Res., vol. 101, no. B5, pp. 11 579-11 588, May 1996.

[11] N. C. Grody and A. N. Basist, "Global identification of snowcover using SSM/I measurements," IEEE Trans. Geosci. Remote Sens., vol. 34, no. 1, pp. 237-249, Jan. 1996.

[12] B. Yan and F. Weng, "Intercalibration between special sensor microwave imager/sounder and special sensor microwave imager," IEEE Trans. Geosci. Remote Sens., vol. 46, no. 4, pp. 984-995, Apr. 2008.

[13] H. J. Kramer, Observation of the Earth and Its Environment?: Survey of Missions and Sensors?, 4th ed. New York, NY, USA: Springer-Verlag, 2002.

[14] T. Wilheit, R. Adler, S. Avery, E. Barrett, P. Bauer, W. Berg, A. Chang, J. Ferriday, N. Grody, S. Goodman, C. Kidd, D. Kniveton, C. Kummerow, A. Mugnai, W. Olson, G. Petty, A. Shibata, and E. A. Smith, "Algorithms for the retrieval of rainfall from passive microwave measurements," $R e$ mote Sens. Rev., vol. 11, no. 1-4, pp. 163-194, 1994.

[15] C. Textor, H. F. Graf, M. Herzog, J. M. Oberhuber, W. I. Rose, and G. G. J. Ernst, "Volcanic particle aggregation in explosive eruption columns. Part I: Parameterization of the microphysics of hydrometeors and ash," J. Volcanol. Geotherm. Res., vol. 150, no. 4, pp. 359-377, Feb. 2006.

[16] C. Textor, H. F. Graf, A. Longo, A. Neri, T. Esposti Ongaro, P. Papale, C. Timmreck, and G. J. Ernst, "Numerical simulation of explosive volcanic eruptions from the conduit flow to global atmospheric scales," Ann. Geophys., vol. 48, no. 4/5, pp. 817-842, Aug./Oct. 2005.

[17] J. M. Oberhuber, M. Herzog, H. F. Graf, and K. Schwanke, "Volcanic plume simulation on large scales," J. Volcanol. Geotherm. Res., vol. 87, no. 1-4, pp. 29-53, Dec. 1998. 
[18] C. Textor, H. F. Graf, M. Herzog, and J. M. Oberhuber, "Injection of gases into the stratosphere by explosive volcanic eruptions," J. Geophys. Res., vol. 108, no. D19, pp. 1-17, Oct. 2003.

[19] M. Herzog, H.-F. Graf, C. Textor, and J. M. Oberhuber, "The effect of phase changes of water on the development of volcanic plumes," $J$. Volcanol. Geotherm. Res., vol. 87, no. 1-4, pp. 55-74, Dec. 1998.

[20] H. Masunaga, T. Matsui, W.-K. Tao, A. Y. Hou, C. D. Kummerow, T. Nakajima, P. Bauer, W. S. Olson, M. Sekiguchi, and T. Y. Nakajima, "Satellite data simulator unit: A multisensor, multispectral satellite simulator package," Bull. Amer. Meteorol. Soc., vol. 91, no. 12, pp. 1625-1632, Dec. 2010.

[21] T. Thordarson and G. Larsen, "Volcanism in Iceland in historical time: Volcano types, eruption styles and eruptive history," J. Geodyn., vol. 43, no. 1, pp. 118-152, Jan. 2007.

[22] V. M. Kerminen, J. V. Niemi, H. Timonen, M. Aurela, A. Frey, S. Carbone, S. Saarikoski, K. Teinilä, J. Hakkarainen, J. Tamminen, J. Vira, M. Prank, M. Sofiev, and R. Hillamo, "Characterization of a volcanic ash episode in southern Finland caused by the Grimsvötn eruption in Iceland in May, 2011," Atmos. Chem. Phys., vol. 11, no. 23, pp. 12227-12 239, Dec. 2011.

[23] S. Barsotti, A. Neri, and J. S. Scire, "The VOL-CALPUFF model for atmospheric ash dispersal: 1. Approach and physical formulation," $J$. Geophys. Res., vol. 113, no. B3, pp. 1-12, Mar. 2008.

[24] B. Langmann, "Numerical modelling of regional scale transport and photochemistry directly together with meteorological processes," Atmos. Environ., vol. 34, no. 21, pp. 3585-3598, 2000.

[25] A. Stohl, M. Hittenberger, and G. Wotawa, "Validation of the Lagrangian particle dispersion model FLEXPART against large scale tracer experiment data," Atmos. Environ., vol. 32, no. 24, pp. 4245-4264, Dec. 1998.

[26] F. S. Marzano, S. Marchiotto, C. Textor, and D. Schneider, "Modelbased weather radar remote sensing of explosive volcanic ash eruption," IEEE Trans. Geosci. Remote Sens., vol. 48, no. 10, pp. 3591-3607, Oct. 2010.

[27] B. Oddsson, M. T. Gudmundsson, G. Larsen, and S. Karlsdóttir, "Monitoring of the plume from the basaltic phreatomagmatic 2004 Grímsvötn eruption-Application of weather radar and comparison with plume models," Bull. Volcanol., vol. 74, no. 6, pp. 1395-1407, Aug. 2012.

[28] R. Showstack, "Iceland's Grímsvötn volcano erupts," EOS Trans. Amer. Geophys. Union, vol. 92, no. 22, p. 187, 2011.

[29] H. Masunaga and C. D. Kummerow, "Combined radar and radiometer analysis of precipitation profiles for a parametric retrieval algorithm," $J$. Atmos. Ocean. Technol., vol. 22, no. 7, pp. 909-929, Jul. 2005.

[30] P. Bauer, E. Moreau, F. Chevallier, and U. O'Keefe, "Multiplescattering microwave radiative transfer for data assimilation applications," Q. J. R. Meteor. Soc., vol. 132, no. 617, pp. 1259-1281, Apr. 2006.

[31] F. S. Marzano, "Modeling antenna noise temperature due to rain clouds at microwave and millimeter-wave frequencies," IEEE Trans. Antennas Propag., vol. 54, no. 4, pp. 1305-1317, 2006.

[32] A. B. Rogers, D. G. Macfarlane, and D. A. Robertson, "Complex permittivity of volcanic rock and ash at millimeter wave frequencies," IEEE Geosci. Remote Sens. Lett., vol. 8, no. 2, pp. 298-302, Mar. 2011.

[33] R. J. Adams, W. F. Perger, W. I. Rose, and A. Kostinski, "Measurements of the complex dielectric constant of volcanic ash from 4 to $19 \mathrm{GHz}$," $J$. Geophys. Res., vol. 101, no. B4, pp. 8175-8185, Apr. 1996.

[34] F. S. Marzano, M. Lamantea, D. Cimini, M. Montopoli, M. Herzog, and H. Graf, "Passive microwave remote sensing of Plinian eruption due to the Grímsvötn Icelandic volcano," in Proc. 12th Spec. Meeting MicroRad Remote Sens. Environ., Rome, Italy, Mar. 5-9, 2012, pp. 1-4.

[35] F. S. Marzano, S. Barbieri, G. Vulpiani, and W. I. Rose, "Volcanic ash cloud retrieval by ground-based microwave weather radar," IEEE Trans. Geosci. Remote Sens., vol. 44, no. 11, pp. 3235-3246, Nov. 2006.

[36] A. J. Prata, "Infrared radiative transfer calculations for volcanic ash clouds," Geophys. Res. Lett., vol. 16, no. 11, pp. 1293-1296, Nov. 1989.

[37] C. Bonadonna, R. Genco, M. Gouhier, M. Pistolesi, R. Cioni, F. Alfano, A. Hoskuldsson, and M. Ripepe, "Tephra sedimentation during the 2010 Eyjafjallajökull eruption (Iceland) from deposit, radar, satellite observations," J. Geophys. Res., vol. 116, no. B12, p. B12 202, Dec. 2011.

[38] S. J. English and T. J. Hewison, "Fast generic millimeter wave emissivity model," in Proc. SPIE Conf--Microwave Remote Sensing Atmosphere Environment, Beijing, China, 1998, pp. 288-300.

[39] C. G. Newhall and S. Self, "The volcanic explosivity index (VEI) an estimate of explosive magnitude for historical volcanism," J. Geophys. Res., vol. 87, no. C2, pp. 1231-1238, Feb. 1982.

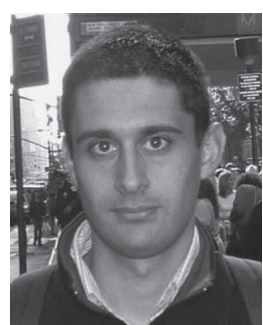

Mario Montopoli received the Laurea degree in electronic engineering from the University of L'Aquila, L'Aquila, Italy, in 2004 and the the Ph.D. degree from the University of Basilicata, Potenza, Italy, and Sapienza University of Rome, Rome, Italy, in 2008 .

In 2005, he joined the Centro di Eccellenza per l'integrazione di Tecniche di Telerilevamento e Modellistica Numerica per la Previsione di Eventi Meteorologici Severi, University of L'Aquila, where he studied ground-based radar meteorology and microwave remote sensing. In 2006, he was with the Department of Electrical Engineering and Information, University of L'Aquila. Since October 2011, he has been with the Department of Geography, University of Cambridge, Cambridge, U.K., under the Marie Curie FP7 fellowship. He is currently working on volcanic remote sensing to combine and compare information derived from spatiotemporal simulation models of volcanic clouds and satellite and ground-based observations recorded for past volcanic eruptions. In the recent years, he has focused on aspects of atmospheric remote sensing using electromagnetic models (scattering model from hydrometeor particles and radiative transfer models) to help the interpretations of measurements obtained from satellite (passive radiometers) and ground-based instruments (radars) with special attention to microwave applications. In the past, he focused on the data integration of GPS sensors and satellite observations at infrared for improving synthetic aperture radar retrievals and development of a coherent radiative model to simulate the energy emission from the layers of the Moon soil within the European Space Agency project "ESMO."

Dr. Montopoli was awarded (as coauthor) for the best oral contribution within the 10th European Geosciences Union (EGU)-Plinius Conference on Mediterranean Storms (Crete, Greece) in 2008. In 2009, he was awarded (as coauthor) for the best oral contribution within the European Conference on Antennas and Propagation (Berlin, Germany). In 2010, he was awarded (as the first author) for the best paper published on an international journal within the European Radar Conference (Sibiu, Romania). In 2011, he was awarded (as coauthor) with the best oral presentation in the 13th EGU-Plinius Conference on Mediterranean Storms.

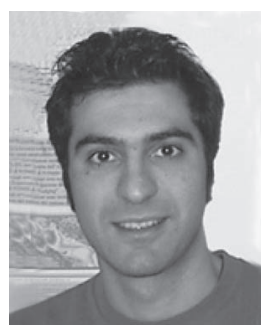

Domenico Cimini received the Laurea (cum laude) and Ph.D. degrees in physics from the University of L'Aquila, L'Aquila, Italy, in 1998 and 2002, respectively.

In 2002-2004, he was with the Centro di Eccellenza per l'integrazione di Tecniche di Telerilevamento e Modellistica Numerica per la Previsione di Eventi Meteorologici Severi (CETEMPS), University of L'Aquila. In 2004-2005, he was a Visiting Fellow with the Cooperative Institute for Research in Environmental Sciences, University of Colorado (CU), Boulder, CO, USA. In 2005-2006, he was with the Istituto di Metodologie per l'Analisi Ambientale, Consiglio Nazionale delle Ricerche (IMAA-CNR), Tito Scalo, Italy, where he worked on ground- and satellitebased observations of cloud properties. Since 2006, he has been an Affiliate of the CU Center for Environmental Technology, Department of Electrical and Computer Engineering, where he served as Adjunct Professor in 2007. Since 2009, he has been sharing the coordination of an international network of ground-based microwave radiometers, MWRnet. He is currently with the Satellite Remote Sensing Division, IMAA-CNR, and also affiliated with CETEMPS, University of L'Aquila.

Dr. Cimini was a recipient of the Fondazione Ugo Bordoni Award in 2008 in memory of Prof. Giovanni D'Auria.

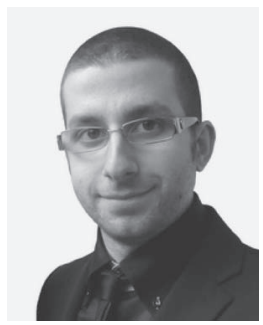

Mirko Lamantea was born in Rome, Italy, in 1986. He received the B.Sc. degree (cum laude) in telecommunication engineering and the M.Sc. degree (cum laude) in communication engineering from Sapienza University of Rome, Rome, in 2008 and 2011, respectively.

Since 2010, he has been with the Department of Information Engineering, Electronics and Telecommunications, Sapienza University of Rome, cooperating on radar remote sensing of volcanic ash clouds. His current interests are passive and active environmental remote sensing techniques, image and radar signal processing, and electromagnetic inversion problems. 


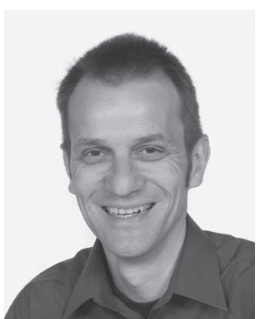

Michael Herzog received the Diploma in physics from the University of Bonn, Bonn, Germany, in 1992 and the Ph.D. degree (summa cum laude) from the University of Hamburg, Hamburg, Germany, in 1998, after performing his Ph.D. work at the Max Planck Institute for Meteorology, Hamburg.

He is currently with the Department of Geography, University of Cambridge, Cambridge, U.K. Before joining the University of Cambridge as a Lecturer in 2007, he was a Research Scientist with the University of Michigan, Ann Arbor, MI, USA, and the Geophysical Fluid Dynamics Laboratory, Princeton, NJ, USA. He is one of the main developers of the nonhydrostatic plume model ATHAM. His main research interests include the development of numerical models to study the interaction between dynamical and microphysical processes in volcanic plumes and convective clouds. He has published more than 40 publications in peerreviewed journals.

Dr. Herzog is a member of the American Geophysical Union and the European Geophysical Union.

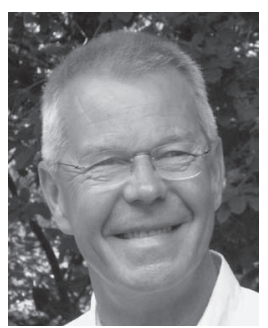

Hans Friedrich Graf received the Diploma degree in meteorology, the Ph.D. (Dr. rer. nat.) degree in meteorology, and the Habilitation in Sciences (Dr.Sc.) degree from Humboldt University of Berlin, Berlin, Germany, in 1974, 1979, and 1989, respectively.

He was a Scientific Assistant with the Division of Physics, Humboldt University of Berlin, from 1974 to 1978 , an Industrial Meteorologist with Kombinat Kraftwerksanlagenbau, Berlin, from 1978 to 1979 , a Scientific Assistant (tenured) with the Meteorological Institute, Humboldt University of Berlin, from 1979 to 1990, and a Senior Scientist and a Group Leader with the MaxPlanck-Institute for Meteorology, Hamburg, Germany, from 1991 to 2003. He is currently a Professor of environmental system analysis with the University of Cambridge, Cambridge, U.K. His scientific research has always been a mixture of modeling and data analysis, examining all time and space scales of climate variations, from cloud microphysics to global general circulation. Recently, he has concentrated on processes of relevance to climate change, and during the last years, he is more focused on physicochemical aspects of climate change, particularly aerosols, stratospheric ozone, and fundamental modes of general circulation. Furthermore, he is involved in volcano and biomass burning plume modeling. A recent field is the modeling and parameterization of convective clouds for use in noncloud resolving models, which allows for consideration of chemistry-aerosol-microphysics processes. He has taken part as Principal Investigator in several German national research programs, the Ozone Program, the Climate Research Program, Baltic Sea Experiment, the German Aerosol Research Focus (started at his initiative), the Atmospheric Research Programme 2000, The Influence of Solar Radiation Perturbations on the Coupling of Atmospheric Layers, smoke aerosols, clouds, rainfall and climate: Aerosols from biomass burning perturb global and regional climate, present and retrospective state of organic versus inorganic aerosol over Europe (Fifth Framework Program-European Union), and EU FW6 projects SCOUT-O3 and INSIDE (an Asia-Pro-Eco initiative); as Coordinator of the FW5 EU Programme PARTS; as Co-PI in two Natural Environment Research Council-sponsored consortium projects (OP3-Danum and one on stratosphere-troposphere interaction); and as Principal Investigator DFG of the Tibetan Plateau: Formation-Climate-Ecosystems. He has authored and coauthored more than 160 journal and book publications.

Prof. Graf has been a member of the American Geophysical Union since 1991, the European Geophysical Union since 1999, and Deutsche Meteorologische Gesellschaft since 1975 (awarded with Sühring Medal in 1989).



Frank Silvio Marzano (S'89-M'99-SM'03) received the Laurea degree (cum laude) in electrical engineering and the Ph.D. degree in applied electromagnetics from Sapienza University of Rome, Rome, Italy, in 1988 and 1993, respectively.

After being with the Italian Space Agency (ASI) and a Lecturer with the University of Perugia, Perugia, Italy, in 1997, he joined the Department of Electrical Engineering and cofounded the Centro di Eccellenza per l'integrazione di Tecniche di Telerilevamento e Modellistica Numerica per la Previsione di Eventi Meteorologici Severi (CETEMPS), University of L'Aquila, L'Aquila, Italy. In 2005, he joined the Department of Electronic Engineering (now Department of Information Engineering, Electronics and Telecommunications), Sapienza University of Rome, where he currently teaches courses on antenna theory, electromagnetic propagation, and remote sensing. Since 2007, he has also been the Vice-Director of CETEMPS, University of L'Aquila. His current research concerns passive and active remote sensing of the atmosphere from ground-based, airborne, and spaceborne platforms, development of inversion methods, radiative transfer modeling of scattering media, and radar meteorology issues. He is also involved on radio and optical propagation topics in relation to incoherent wave modeling, scintillation prediction, and rain fading analysis along terrestrial and satellite links. Within 2001-2005, he was the Italian National Delegate for the European COoperation in the field of Scientific and Technical research (COST) actions n. 720 and n. 280; since 2008, he has been the National Delegate for the European COST Action project ES702 "EGCliMet" and COST Action project IC0802 "PropTNEO." He coedited two books on remote sensing for Springer-Verlag (Berlin, Germany) in 2002 and 2010. He is a Reviewer for the major international journals in remote sensing, geoscience, and propagation. Since 2011, he has been an Associate Editor of the European Geosciences Union (EGU) Atmospheric Measurement Techniques journal. He has published 100 papers on international refereed journals, 30 book chapters, and more than 200 extended abstracts in conference proceedings.

Dr. Marzano is a Senior Member of the IEEE Geoscience and Remote Sensing Society. Since 2010, he has been a member of the European Volcanic Ash Cloud Expert Group. Since January 2004, he has been acting as an Associate Editor of the IEEE GEOSCIENCE AND REMOTE SENSING LETTERS. In 2005 and 2007, he was a Guest Coeditor of the MicroRad04 and MicroRad06 Special Issues for the IEEE TRANSACTIONS ON GEOSCIENCE AND REMOTE SENSING. In 1993, he was the recipient of the Young Scientist Award of the XXIV General Assembly of the International Union of Radio Science (Osaka, Japan). He was the recipient of the Alan Berman Publication Award from the Naval Research Laboratory (Washington, DC, USA) in 1998, the Best Paper Award from the EGU-Plinius Conference (Nicosia, Cyprus) in 2008, and the Best Oral Paper Award on propagation from the EuCAP Conference (Berlin, Germany) in 2009. 